\title{
Why Are Women Slimmer Than Men in Developed Countries?
}

Shiko Maruyama $^{\mathrm{a}, *}$, Sayaka Nakamura ${ }^{\mathrm{b}}$

a Economics Discipline Group, University of Technology Sydney, PO Box 123, Broadway, NSW 2007 Australia, Email: shiko.maruyama@uts.edu.au

${ }^{\mathrm{b}}$ School of Economics, Nagoya University, Furocho, Chikusa, Nagoya, 464-8601 Japan, Email: nakamuras@soec.nagoya-u.ac.jp

*Corresponding author: Economics Discipline Group, University of Technology Sydney, PO Box 123, Broadway, NSW 2007 Australia, Phone: +61 29514 7730, Fax: +61 295147711 , Email: shiko.maruyama@uts.edu.au 


\section{Why Are Women Slimmer Than Men in Developed Countries?}

\section{Abstract}

Women have a lower BMI than men in developed countries, yet the opposite is true in developing countries. We call this the gender BMI puzzle and investigate its underlying cause. We begin by studying time trends in Japan, where, consistent with the cross-country puzzle, the BMI of adult women has steadily decreased since the 1950s, whereas the BMI of adult men has steadily increased. We study how changes in energy intake and energy expenditure account for the over-time gender BMI puzzle using the Japanese National Nutrition Survey from 1975 to 2010, which provides nurse-measured height and weight and nutritionist-assisted food records. Because long-term data on energy expenditure do not exist, we calculate energy expenditure using a steady-state body weight model. We then conduct cross-country regression analysis to corroborate what we learn from the Japanese data.

We find that both energy intake and energy expenditure have significantly decreased for Japanese adult men and women and that a larger reduction in energy expenditure among men than women accounts for the increasing male-to-female BMI gap. Trends in BMI and energy expenditure vary greatly by occupation, suggesting that a relatively large decrease in physical activity in the workplace among men underlies the gender BMI puzzle.

The cross-country analysis supports the generalizability of the findings beyond the Japanese data. Furthermore, the analysis suggests the increasing male-to-female BMI gap is driven not only by a reduction in the energy requirements of physically demanding work but also by weakening occupational gender segregation. No support is found for other explanations, such as increasing female labor force participation, greater female susceptibility to malnutrition in utero, and gender inequality in nutrition in early life.

Keywords: Body mass index, steady-state body weight, physical activity, energy intake, energy accounting, occupational gender segregation 


\section{Introduction}

Cross-country analysis shows that the obesity rate is higher among women than among men in low-income countries (Wells et al., 2012). Similarly, women have a higher risk of obesity than men do among minority groups (Wardle et al., 2002; Thorburn, 2005; Katzmarzyk, 2008; Flegal et al., 2010) and among individuals with a low socioeconomic background (Case and Menendez, 2009; Robinson, 2012). We find that this pattern holds more generally. Figure 1 shows the body mass index (BMI) of men and women across selected countries (BMI is defined as [weight in kilograms] / [height in meters] $]^{2}$ ). Regardless of the average BMI level of each country, the average female BMI is higher than the average male BMI in developing countries, and the opposite is true in developed countries. We call this phenomenon the gender BMI puzzle.

The literature offers a number of potential explanations for this puzzle. The conventional explanation posits that early-life malnutrition leads to adult obesity and that the obesity prevalence is higher for women than for men due to greater female exposure to malnutrition (Wells et al., 2012) and greater female susceptibility to perinatal nutritional restriction (the fetal origin hypothesis) (Robinson, 2012). The marriage market might be relevant because physical attractiveness is more important in the male choice for women than in the female choice for men (Averett and Korenman, 1996; Fisman et al., 2006) and because men in high-income groups/countries tend to prefer women with a low BMI compared to men in low-income groups/countries (Swami, 2006). Women in lower-income countries might gain more weight from more frequent childbirth than women in higher-income countries do. Finally, the fact that physically demanding jobs, especially blue-collar jobs, are traditionally held by men (occupational gender segregation) might also explain the gender BMI puzzle in two ways. First, if technological development reduces the energy requirement in physically 
demanding jobs more than in other jobs, male energy expenditure decreases relative to female energy expenditure. Second, if social development weakens occupational gender segregation, women's energy expenditure at work increases relative to men.

We provide new insights into the mechanism behind the gender BMI puzzle by studying individual-level data drawn from the 1975-2010 Japanese National Nutrition Survey (NNS) and cross-country data. The time-series dataset in Japan offers a unique opportunity to identify the main intertemporal driver behind the gender BMI puzzle: the age-specific BMI of adult women in Japan has steadily decreased since the 1950s, whereas the BMI of adult men has consistently increased (Funatogawa et al., 2009; Maruyama and Nakamura, 2015). A large body of nutrition science literature agrees that the long-term BMI trend is due to energy imbalance (i.e., an excess of energy intake over energy expenditure) (e.g., Bleich et al., 2008). Hence, we studied how changes in energy intake and energy expenditure over time account for the gender difference in BMI trends. To the best of our knowledge, this is the first such undertaking. Previous studies have focused on cross-country variation in female excess in obesity (Wells et al., 2012).

The NNS is presumably one of the best available data sources for height, weight, and food intake in terms of sample representativeness, accuracy, and duration of the survey. The height and weight measurements are recorded by health professionals, and energy intake data are based on nutritionist-assisted food records (Smil and Kobayashi, 2012). To address the lack of reliable long-term data on energy expenditure, we calculated energy expenditure using a steady-state body weight model in which body weight self-adjusts so that energy imbalance resolves. This framework was used to quantify how changes in energy intake and energy expenditure over time contribute to trends in BMI. Furthermore, we examined how trends in energy intake and energy expenditure differ across various subpopulations to explore how 
lifestyle and socioeconomic environments underlie the gender BMI puzzle. We then conducted a cross-country analysis to corroborate the generalizability of our findings beyond the Japanese data and to obtain further insights into the cause of the gender BMI puzzle.

The analysis of the NNS reveals that the direct cause of the increasing male-to-female BMI gap is differential changes in physical activity levels between men and women. In Japan, energy intake and energy expenditure have steadily decreased among adults in all gender and age groups. The reason the average male BMI has increased and the average female BMI has decreased is that although the decrease in energy intake is similar for both men and women, the decrease in energy expenditure is greater among men than among women.

Why did men's physical activity level decline faster than that of women? We find that trends in energy expenditure differ significantly by occupation, suggesting the substantial role of occupational gender segregation. The results from the cross-country analysis indicate that male BMI is higher than female BMI in countries with smaller occupational gender segregation and that economic development makes men heavier than women only in countries where more men than women work in physically demanding occupations. Overall, our findings suggest two mechanisms behind the gender BMI puzzle: weakening occupational gender segregation and a reduction in energy requirements at work. No support is found for other explanations, such as increasing female labor force participation, marriage market and fertility hypotheses, greater female susceptibility to malnutrition in utero, and gender inequality in nutrition in early life.

\section{Framework for Energy Accounting Analysis}

Using individual-level data drawn from the 1975-2010 Japanese National Nutrition Survey (NNS), we construct the time-series data of energy intake and energy expenditure. We 
compare trends in energy intake and energy expenditure between men and women to identify the main driver behind the gender BMI puzzle. As a more formal, mathematical description, we also derive a decomposition of the gender difference in BMI trends into the gender differences in energy intake and energy expenditure trends.

\subsection{Data}

The NNS is a nationally representative annual cross-sectional survey conducted by the Ministry of Health, Labour and Welfare. This survey was renamed the National Health and Nutrition Survey in 2003, but we use the abbreviation NNS throughout the paper. Further details of the NNS and the data construction are provided in Appendix 1. We restricted our attention to individuals aged 18-59. Pregnant and lactating women and children were excluded from the main analysis because our steady-state model may not hold for them, although we conducted the analysis for children aged 10-17 to compare the results. We excluded the elderly because BMI and mortality may be related, and longevity trends in the sample may have confounded BMI trends. The total sample size over our study period was 245,880 .

Our main dataset consisted of age, gender, height, weight, and food intake. Overall, the NNS data are reliable; reporting bias and misreporting are of limited concern. Height and weight were measured without shoes by health professionals with adjustments for the weight of clothes. Nutritional intake data were compiled from a nutritionist-assisted food intake questionnaire. "The person in charge of cooking" in the household was instructed to use scales for measurement and to record the food items and the amounts consumed by the household during the survey period. A certified nutritionist visited each participating household to provide further guidance and to correct for misreporting. We examined the 
validity of the food intake data in the NNS using Goldberg et al.'s (1991) method (see Appendix 1) and found that under-reporting of food intake was considerably less prevalent than in similar surveys.

Figure 2 presents the trends in mean height, weight, and BMI by gender and age group in our sample. Height and weight increased for both genders across all age groups. Although male height and female height increased at similar rates, female weight increased more slowly than male weight did. Consequently, BMIs increased for men and decreased for women. These findings are consistent with previous studies based on aggregate NNS data (Funatogawa et al., 2009; Maruyama and Nakamura, 2015). ${ }^{1}$

\subsection{The Steady-State Weight Model}

The NNS has information on physical activity, but the definition of "physical activity" has changed frequently and substantially, which makes over-time comparison impossible. Moreover, we know of no other reliable data on long-term trends in the physical activity level in Japan. ${ }^{2}$ Thus, we used an alternative approach and calculated a long time-series of

\footnotetext{
${ }^{1}$ In this paper, we focus on mean BMI. Further investigation of the distributions of BMI
} between the years 1975-1979 and 2005-2010 using kernel density estimation reveals that for all gender and age groups, over-time changes in mean BMI are caused by a shift of the entire distribution.

2 The physical activity level can be accurately measured nowadays using doubly-labeled water (DLW) method, but few DLW studies cover periods before the 1990s, and the existing DLW studies are based on small samples that are not representative of any population (Millward, 2013). 
physical activity levels using the concept of steady-state weight. Although we are unaware of any study that has constructed a time-series of energy expenditure in this way, the steady-state weight framework has been widely used in the literature (Cutler et al., 2003; Michaud et al., 2007; Bleich et al., 2008; Ruhm, 2012). The framework assumes that, in the absence of substantial changes in energy intake and energy expenditure, body weight eventually converges to a weight that resolves energy imbalance. The novelty of our analysis is the use of this steady-state relationship to "reverse engineer" energy expenditure from the energy intake and body weight data.

On the energy expenditure side, our model is based on the fact that humans burn energy through three channels: basal metabolism, physical activity, and the thermic effect of food (Jéquier and Tappy, 1999). Basal metabolism refers to the energy expenditure required to keep the body alive and functioning at rest. The energy expenditure required for a given level of physical activity is proportional to body weight (Brooks et al., 2004) in accordance with Newton's second law of motion. The thermic effect of food represents the energy cost associated with digestion, absorption, and the distribution of nutrients, corresponding to approximately $10 \%$ of total energy intake (Westerterp, 2004).

Following Cutler et al.'s (2003) notation, we denote body weight as Weight, daily basal metabolism as $B M$, which is an increasing function of Weight, daily energy intake as $K$, and the index of the physical activity level as $E$, which is measured in daily energy expenditure per body weight kilogram. Based on the approximation discussed above, the following steady-state equality holds:

$$
K=B M\left(\text { Weight }^{*}\right)+E \cdot \text { Weight }^{*}+0.1 \cdot K,
$$

where Weight ${ }^{*}$ is the steady-state body weight given $E$ and $K$ (Cutler et al., 2003; Bleich et al., 2008). This equation can be rewritten as 


$$
0.9 \cdot K=B M\left(\text { Weight }^{*}\right)+E \cdot \text { Weight }^{*} \text {. }
$$

Figure 3 illustrates the model in the weight-calorie space. The upward sloping line denotes the right-hand side (RHS) of Equation (1), and the horizontal line denotes the left-hand side (LHS). The steady-state equality implies that body weight eventually converges to Weight ${ }^{*}$ because when Weight $>$ Weight ${ }^{*}$, the RHS is greater than the LHS, and insufficient energy intake decreases body weight. When Weight $<$ Weight ${ }^{*}$, body weight increases in response to excess energy intake.

Equation (1) enables us to calculate $E$ from the knowledge of current weight, $K$, and the function $B M($ Weight). Because basal metabolism also depends on height, age, and gender, we predicted $B M$ using the following equations from Ganpule et al. (2007):

Male $B M(\mathrm{kcal} /$ day $)=(48.1 \cdot$ Weight $+23.4 \cdot$ Height $-13.8 \cdot$ Age -423.5$) / 4.1868$

Female $B M(\mathrm{kcal} / \mathrm{day})=\left(48.1 \cdot\right.$ Weight $+23.4 \cdot$ Height$^{-13.8} \cdot$ Age $\left.^{-970.8}\right) / 4.1868$, where Weight is weight in kilograms, Height is height in centimeters, and Age is age in years. Equations (2) and (3) are substituted to Equation (1) to calculate $E$ of individual males and females, respectively. See Appendix 1 for details of these two equations.

There are two potential concerns that might undermine the validity of our approach. First, at the individual level, observed data points may diverge from steady-state values due to daily variations in energy intake and energy imbalance caused by lifestyle changes (e.g., dieting for weight reduction). However, the aggregate cell mean of $E$ by age and gender is unbiased if $K$ 's deviation from the steady-state level is distributed with a mean of zero, as shown in Appendix 2. Second, if a non-negligible energy imbalance remains at the aggregate level, our steady-state framework fails. This may occur when the entire country experiences rapid, drastic weight change, as in famine and wartime. Michaud et al. (2007) also argue that the steady-state approach is more appropriate for older individuals than for younger 
individuals because the former are less prone to unstable changes in body weight and lifestyle than the latter. However, the weight change among Japanese adults was moderate and considerably smaller than in other developed countries. In our data, after excluding individuals younger than 18 , the largest 10 -year weight change by gender, cohort, and decade was a gain of $4.3 \mathrm{~kg}$ between the 1990s and 2000s among men born in the $1970 \mathrm{~s}$, and the daily energy imbalance required for a weight change of this magnitude is unmeasurably small. These facts make the second concern unimportant.

This analysis focuses on the comparison of trends in BMI, $E$, and $K$ between men and women rather than levels. Comparing the levels of $E$ and $K$ is not informative in understanding the gender difference in BMI due to large gender differences in underlying basal metabolism, height, and weight.

\subsection{Decomposing BMI Trends}

To quantify the contributions of height, energy intake, and energy expenditure to BMI trends, we conducted the following decomposition analysis by gender and age group. Let $\Delta \overline{B M I_{t}}$ denote the change in the average BMI of a group between the base period, 1975-79, and year $t$. Given Equations (1) to (3) and the definition of BMI, the steady-state BMI can be expressed as the general function

$$
B M I_{t}^{*}=B M I^{*}\left(K_{t}, E_{t}, \text { Height }_{t}, \text { Age }_{t}\right) .
$$

The first-order Taylor expansion of equation (4) over E, K, Height, and Age is

$$
\begin{aligned}
& \Delta \overline{B M I_{t}} \approx B M I_{E}^{*}\left(\overline{K_{t}}, \overline{E_{t}}, \overline{\text { elght }_{t}}, \overline{A g e_{t}}\right) \cdot \Delta \overline{E_{t}}+B M I_{K}^{*}\left(\overline{K_{t}}, \overline{E_{t}}, \overline{\text { Helght }_{t}}, \overline{\operatorname{Age}_{t}}\right) \cdot \Delta \overline{K_{t}}+ \\
& B M I_{H}^{*}\left(\overline{K_{t}}, \overline{E_{t}}, \overline{\text { Herght }_{t}}, \overline{\operatorname{Age}_{t}}\right) \cdot \Delta \overline{\operatorname{Helght}_{t}}+B M I_{A}^{*}\left(\overline{K_{t}}, \overline{E_{t}}, \overline{\text { Helght }_{t}}, \overline{A g e_{t}}\right) \cdot \Delta \overline{\operatorname{Age}_{t}},
\end{aligned}
$$

where $\Delta$ denotes the change in each variable, and the subscripts to $B M I($.) represent partial differentiation with respect to each variable. Equation (5) decomposes a change in BMI into 
each variable's contribution, defined as the change in each variable times its partial differentiation coefficient. For example, $E$ 's contribution is given by $\operatorname{BMI}_{E}^{*}\left(\overline{K_{t}}, \overline{E_{t}}, \overline{\text { Helght }_{t}}, \overline{\operatorname{Age}_{t}}\right) \cdot \Delta \bar{E}_{t}$.

\section{Results from Japanese Data}

\subsection{Trends in BMI, Energy Intake, and Energy Expenditure}

Figure 4 shows the trends in the means of BMI, $E$, and $K$ from 1975 to 2010 by gender for four age groups: 18-29, 30-39, 40-49, and 50-59. As discussed earlier, the average BMI increased among men and decreased among women. At the same time, both $E$ and $K$ decreased over time in each age and gender group. This finding immediately rejects the hypothesis that the increase in the average male BMI was driven by an increase in energy intake.

Figure 4 also shows that the decrease in $E$ was greater among men than among women in all age groups, whereas $K$ decreased similarly for both men and women. This finding illustrates that the gender BMI puzzle is driven by the gender difference in the $E$ trend.

\subsection{Decomposition}

Using Equation (5), we decomposed the male-female difference in percentage changes in BMI to the contributions of energy intake, energy expenditure, and height. Figure 5 illustrates the decomposition results (see Appendix 3 for numerical results). Male-female differences are shown as cumulative percentage changes in BMI, $E$ 's contribution, $K$ 's contribution, and Height's contribution (e.g., [\% change in E's contribution to the male $B M I]-[\%$ change in E's contribution to the female BMI]). The cumulative percentage change 
is relative to the base period 1975-1979. Because the contribution of age is negligible, we subtracted it from the change in BMI and show the age-adjusted values; the blue dashed lines show $([\%$ change in the male $B M I]-[\%$ change in age's contribution to the male $B M I])-([\%$ change in the female BMI]-[\% change in age's contribution to the female BMI]).

All age groups show consistent patterns. The male-female difference in BMI has enlarged over time. $E$ contributes positively to the difference, $K$ contributes negatively, and Height contributes little. Thus, the increasing gender gap in adult BMI results from the increasing gender difference in $E$.

\subsection{Other Explanations}

The obesity literature suggests other potential determinants of BMI trends. It is important to examine whether the gender BMI puzzle in Japan can be explained by alternative hypotheses proposed in the literature because our decomposition analysis is silent about the underlying causes of trends in $E$ and $K$. In Appendix 4, we discuss other potential explanations, including lower food price due to increasing food supply, changes in macronutrient composition, eating behavior, and lifestyles, such as sleep duration and smoking. We find that none of these can account for the gender BMI puzzle in Japan.

\section{Sub-Sample Analysis: What Accounts for the Gender Difference in $E$ Trends?}

The next question is why the reduction in men's energy expenditure was greater than that of women. In this section, we explore this question by repeating the above analysis by sub-sample.

\subsection{Results for Children}


We examined whether a gender difference exists in the $E$ and $K$ trends among children. Because Equations (2) and (3) are valid only for adults, we used Molnár et al.'s (1995) results to estimate their $E$. See Appendix 1 for further details. ${ }^{3}$ Panel A of Figure 6 presents the trends in BMI, $E$, and $K$, by gender, for children aged $10-17$. In contrast to the large gender difference among adults, children's trends in BMI, $E$, and $K$ are highly similar for both boys and girls. This finding is consistent with previous studies that find little gender difference in trends of Japanese children's height, weight, and BMI (Kagawa et al., 2011; Maruyama and Nakamura, 2015). The lack of gender difference in childhood suggests the important role of gender difference in adult environments and does not support the in-utero or early life nutritional inequality hypotheses for Japan.

\subsection{Cohort Analysis}

Maruyama and Nakamura (2015) find that the decreasing BMI trend among adult women in post-war Japan is a cohort-specific phenomenon rather than a period-specific phenomenon; that is, the female BMI trend has been driven by changes across birth cohorts over time rather than changes over the life course within a birth cohort. This finding implies that the increase in the male-female difference in BMI is also cohort-specific rather than period-specific and that both genders have similar BMI trends within a cohort. To examine whether the same applies to the within-cohort trends for $E$ and $K$, we present cohort-specific

\footnotetext{
${ }^{3}$ Caution is needed in interpreting the estimated trend in $E$ among children because the steady-state assumption might not hold for children, whose weight and height are growing rapidly. However, the potential violation of the assumption does not affect our main conclusion in Section 4.1 because our focus is on the gender difference in trends rather than the trends themselves.
} 
trends in BMI, $E$, and $K$ by gender in Panel B of Figure 6 . Because the results are similar across birth cohorts, the presentation is limited to the cohort born during the 1940s, which provides the longest time window of adulthood. As expected, and in contrast to age-specific trends, BMI trends are similar between men and women. For both genders, the rates of decrease in $E$ and $K$ are similar, indicating that the gender difference in the BMI trend is driven by the gender difference in the across-cohort trend of $E$ rather than the within-cohort trend of $E$.

\subsection{Comparison by Marital Status}

Previous studies find that prenuptial BMI and obesity are negatively associated with the propensity for marriage only in women but not in men (Mukhopadhyay, 2008; Frisco et al., 2012) and that men's ideal female body weight is lower in higher-income societies (Swami, 2006). Therefore, if Japanese men's preference for women with a low BMI has strengthened over time, as suggested in Swami (2006), this may account for the gender BMI puzzle. To investigate this marriage market hypothesis, Figure 7 compares the trends in BMI, $E$, and $K$ by gender and marital status for younger adults aged $18-39 .^{4}$

Married men and women have a higher BMI than their unmarried counterparts, consistent with previous studies (Averett et al., 2008; Dinour et al., 2012). Nevertheless, when examining the trends of $E$ and $K$ by marital status, we observe little difference, which offers no support for the marriage market hypothesis. Declining fertility may also explain the

\footnotetext{
${ }^{4}$ Because the NNS does not identify relationships among household members, we categorized individuals with an adult opposite-sex household member close in age (within 15 years) as married and those without as unmarried.
} 
gender BMI puzzle because of pregnancy-related and post-pregnancy weight gains, but Figure 7 rejects this hypothesis as well because the gender BMI puzzle exists regardless of marital status.

\subsection{Comparison by Occupation}

Energy expenditure depends primarily on occupation and work style. According to $\mathrm{Ng}$ and Popkin (2012), American adults spend 56\% of their total energy expenditure from physical activity on occupational activities, with $26 \%$ spent on domestic activities, $11 \%$ on travel, and $7 \%$ on active leisure. Previous studies have found that work-related exercise has weight-reducing effects (Lakdawalla and Philipson, 2007, 2009; Sarma et al., 2014; Godard, 2016). These findings lead to the hypothesis that the gender difference in the $E$ trend is generated by trends in work-related energy expenditure.

We thus compared the trends in BMI, $E$, and $K$ by gender and occupation for adults aged 22-59. We excluded participants under 22 to avoid results confounded by school attendance. We categorized men into farmworkers and non-farmworkers and women into farmworkers (including non-working women in farming households), non-farmworkers, and non-workers. We omitted non-working men from the analysis because they are a minority. Among working men, $11.1 \%$ were farmworkers in the late 1970s, and this number decreased to $3.6 \%$ by the late $2000 \mathrm{~s}$. Among women, the proportions of farmworkers, non-farmworkers, and non-workers were $11.9 \%, 40.4 \%$, and $47.7 \%$, respectively, in the late 1970 s versus $2.2 \%$, $64.5 \%$, and $33.4 \%$, respectively, by the late 2000 s.

Figure 8 shows the results. The most notable finding is the increasing BMI trend of female farmworkers, which is rather similar to that of male farmworkers. Likewise, both genders share similar trends for $E$ and $K$. By contrast, female non-farmworkers and female 
non-workers exhibit trends similar to those in the full sample: their BMI decreases while the male BMI increases, and the decrease in $E$ is slower than that of male non-farmworkers. Among men, farmworkers and non-farmworkers share similar trends, though $E$ in male non-farmworkers has decreased slightly faster than it has in male farmworkers. These results indicate the significant role of energy requirements for work with regard to the gender difference in the $E$ trend.

The plotted trends in BMI, $E$, and $K$ in Figure 8 might be affected by changes in age composition in each occupation, particularly by rapid aging among farmworkers and increased female labor force participation. To address this concern, we decomposed the gender gap in the BMI trend to $E, K$, height, and age. We confirm that considering age does not affect our findings, as detailed in Appendix 3.

\subsection{Discussion}

The two main results of the analysis of the Japanese NNS are as follows: (1) the gender BMI puzzle is driven by differential trends in energy expenditure; and (2) much of the gender difference in the energy expenditure trend is likely attributed to differential trends in energy requirements at work. The second result is supported by the findings that no gender difference is observed for teenagers and that differential trends by gender are not a within-cohort but rather an across-cohort phenomenon (because occupational composition changes much less within a cohort than across cohorts).

The remaining question is the mechanism that generates the gender difference in the declining trend of $E$. A potential explanation is the increase in the female labor force participation rate over time. If workers consume more energy than non-workers do, an increase in the proportion of working women lowers the average BMI of women relative to 
men. However, the results of the NNS do not support this hypothesis. As shown in Figure 8, female BMI decreased for non-farmworkers and non-workers alike.

Another potential explanation is a reduction in energy requirements at work ("reduction in work intensity") under occupational gender segregation. A reduction in energy requirements at work is a common phenomenon in societies where machines have replaced manual labor (Ng and Popkin, 2012). This hypothesis posits that the reduction in work intensity is more prevalent in occupations held predominantly by men and thus requires pre-existing occupational gender segregation (but not its weakening trend). This hypothesis is consistent with Figure 8: the groups that experienced the most rapid reduction in energy expenditure were male farmworkers, female farmworkers, and male non-farmworkers. Farming is one of the most physically demanding occupations (Church et al., 2011; Numajiri, 1979).

However, there is another possible explanation that does not contradict Figure 8: the increasing presence of women in physically demanding jobs due to weakening occupational gender segregation. Because occupational gender segregation is large in Japan but has decreased significantly (e.g., OECD, 2012), both a reduction in labor intensity and weakening occupational gender segregation may be at work in the gender BMI puzzle in Japan. We examine these hypotheses further in the next section.

\section{Cross-Country Regression}

\subsection{Empirical Strategy}

In this section, we present the cross-country regressions that explain cross-country variations in the gender difference in BMI. This analysis has two purposes. The first is to confirm whether the insights obtained from Japanese data can be generalized to the global 
context. This is important because one might argue that Japan has a unique obesogenic environment. Japan's prevalence of obesity is one of the lowest among developed countries, and the declining trend in the average female BMI is internationally unique. The second purpose is to obtain further insights into the mechanisms behind the differential trend in workplace energy expenditure.

The dependent variable of the cross-country regression analysis is the male-to-female difference in the mean age-adjusted BMI of a country. Our baseline regression model is as follows:

$$
\Delta \mathrm{BMI}_{i}=\beta_{0}+\beta_{1} \operatorname{lnGDP_{i}}+\beta_{2} \Delta \text { LFParticipation }_{i}+\sum_{r} \alpha_{r}^{R E G I O N}+\varepsilon_{i},
$$

where subscripts $i$ and $r$ stand for country $i$ and region $r$, respectively, $\Delta \mathrm{BMI}$ is [mean age-adjusted male $\mathrm{BMI}]-[$ mean age-adjusted female $\mathrm{BMI}], \ln G D P$ is the natural logarithm of per capita Gross Domestic Product (GDP), $\triangle$ LFParticipation is [male labor force participation rate] - [female labor force participation rate], $\alpha_{r}^{R E G I O N}$ is a region fixed effect for region $r$, and $\varepsilon$ is an error term. We use $\ln G D P$ as a proxy for the developmental stage of each country. By including $\ln G D P$ and the gender gap in the labor force participation rate in the model, we can identify whether the main driver behind the gender BMI puzzle is economic development per se or the gender gap in labor force participation. If, for instance, $\beta_{2}$ is estimated to be negative, this indicates that an increase in the female labor force participation rate lowers the mean BMI of women relative to men.

We also estimate variants of Equation (6) with different sets of controls to examine whether the estimated coefficient on $\triangle$ LFParticipation is robust to the inclusion of other 
variables and to further explore the mechanism by replacing $\Delta$ LFParticipation with more disaggregated measures of the gender gap in labor force participation. ${ }^{5}$

\subsection{Data}

The cross-country dataset for the year 2008 was compiled from several sources. We used the country-level mean age-adjusted BMI by gender in 2008 estimated by Finucane et al. (2011). We obtained data on per capita GDP from the International Monetary Fund's World Economic Outlook Database ${ }^{6}$ and data on gender-specific labor force participation rates from the World Bank's World Development Indicators. ${ }^{7}$ Gender-specific labor force participation rates by occupation were constructed using the working age population size and the number of employees by occupation obtained from the ILOSTAT database. ${ }^{8}$ We used the "major group" codes from the 1988 International Standard Classification of Occupations (ISCO-88). Categories with a small share were combined with the most closely related categories.

The variables used in the regression analysis are listed in Table 1 with their definitions and summary statistics. Mean M-F BMI gap is negative, unlike in the Japanese data, because this dataset contains many developing countries, with $29.1 \%$ of observations being from

5 We did not estimate the full model with all the explanatory variables to simultaneously test multiple hypotheses because the small sample size limits the number of explanatory variables we can include in one specification.

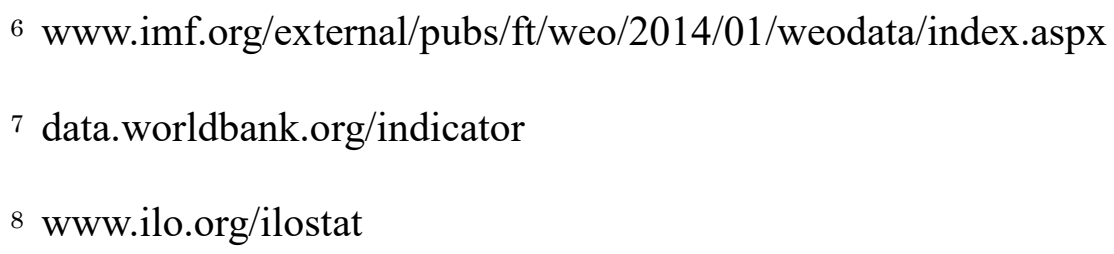


Africa. There were 175 observations after omitting countries whose GDP or labor force participation data were missing. In models with detailed occupation variables, sample sizes were smaller due to data availability. For the list of countries, see Appendix 5.

\subsection{Results}

Table 2 presents the results of various specifications of Equation (6). In Model 1, the simple regression of $M-F$ BMI gap on $\ln G D P$ and $\ln G D P 1988$ ( $\ln G D P$ lagged by 20 years), $\ln G D P$ is significantly positive, indicating lower female BMIs relative to male BMIs in higher-income countries, consistent with the gender BMI puzzle (Figure 1). Model 2 adds M-F labor gap to Model 1 and shows a significantly negative coefficient estimate, implying lower female BMIs relative to male BMIs in countries where the female labor force participation rate is higher relative to the male rate. The coefficient on $\ln G D P$ is significantly positive but becomes insignificant when region dummies are added (Model 3). By contrast, the coefficient on $M-F$ labor gap remains significant, suggesting that the relevant factor for the gender BMI puzzle is M-F labor gap rather than GDP. This finding is consistent with the NNS results, highlighting the importance of work.

Previous studies have attributed female excess in obesity to greater female susceptibility to perinatal malnutrition (Robinson, 2012) and gender inequality in early-life nutrition (Wells et al., 2012). These hypotheses imply that male BMI relative to female BMI is positively associated with economic affluence in the past. However, $\ln G D P 1988$ is not significantly associated with the M-F BMI gap in Models 1-3, showing no support for hypotheses that emphasize past economic affluence.

It is unclear what $M-F$ labor gap captures because it may reflect its correlation with various dimensions of gender inequality. We thus estimated regression models that control for 
various dimensions of women's status, such as the gender inequality index, the proportion of female seats in parliament, the secondary education completion rate for women, maternal mortality (from the United Nations Development Programme), and the total fertility rate (from the United Nations World Population Prospects). Though not reported due to space limitations, the results generally show that if used in place of $M-F$ labor gap, a higher status of women significantly increases $M-F$ BMI gap; however, if $M-F$ labor gap is kept in the regression, $M-F$ labor gap remains significant, and women's status variables have limited explanatory power, highlighting the robust importance of $M-F$ labor $g a p .^{9}$

The statistical significance of $M-F$ labor gap in Models 2 and 3 is insufficient to conclude that the gender BMI puzzle is driven by increasing female labor force participation because the other two hypotheses discussed, weakening occupational gender segregation and reduction in work intensity, are also potentially related to $M-F$ labor gap. To examine these two hypotheses, we included the breakdown of $M-F$ labor gap by occupation in the regression. Model 4 shows the results for the male-to-female employment gap in the seven major occupation groups. Because breakdowns by occupation are not available for all 175 countries, the sample size was reduced to 102. For comparison, we re-estimated Model 3 with the same sample as Model 4 (Model 3a). ${ }^{10}$ The results of Model 3a are highly similar to those of Model 3, implying that the results of Model 4 are not driven by the reduction in sample size.

In Model 4, the coefficients on the M-F gaps in "skilled agriculture," "plant and machine operators and assemblers," and "service and sales occupations" are negative and

\footnotetext{
9 Results are available on request.

$10 \ln G D P 1988$ is excluded because it is missing for some countries. Its inclusion does not affect our main results.
} 
significant. These three occupation groups are energy-demanding jobs according to Church et al. (2011). The gender gaps for the other four occupation groups are statistically insignificant. This result indicates that female BMI relative to male BMI tends to be lower in countries where more women than men work in energy-demanding jobs. Note that we do not include the male-to-female gap for non-workers because it is linearly dependent on the gender gaps for the seven occupation groups. Therefore, the statistical insignificance of the gaps in physically non-demanding occupations implies that an increase in the female labor force participation rate does not affect the gender BMI gap if the increase occurs in these occupations. In contrast, reallocating women to energy-demanding jobs from non-working status or the other four occupation groups decreases female BMI relative to male BMI. Model 4 thus reveals that the positive association between the male-to-female BMI gap and per capita GDP in Model 1 is driven not by an increasing female labor force participation rate but by occupational segregation between genders. Additionally, the insignificance of the gender gap in managerial and professional occupations offers no support for Wells et al.'s (2012) hypothesis that economic gender equality in adulthood decreases female excess in obesity prevalence.

Finally, we examined the generalizability of the hypothesis indicated by the Japanese NNS results: the greater reduction in work intensity in predominantly male occupations. We assume that the reduction in energy requirements at work is caused by technological advancements, which can be proxied by per capita GDP. Although $\ln G D P$ is not significantly associated with the gender BMI gap in Models 3-4, a critical premise for this hypothesis to account for the gender BMI puzzle is male predominance in physically demanding occupations. For this reason, we conducted a regression analysis in which we allowed the effect of $\ln G D P$ on $M-F B M I$ gap to vary depending on the degree of the $M-F$ occupation gap. 
Specifically, we first classified the seven occupation groups used in Model 4 into two groups according to their statistical significance: the three statistically significant occupation groups were classified as "physically demanding” and the rest as "physically non-demanding." We calculated the $M-F$ gap for both of these groups. Most countries have a positive $M-F$ gap in both groups (i.e., more men working than women), but 13 countries (13\%) have a zero or negative $M-F$ gap for physically demanding occupations, and 10 countries (10\%) have a zero or negative $M-F$ gap for physically non-demanding occupations. We created indicators for positive $M-F$ gaps in physically demanding and non-demanding occupations and included them and their interaction terms with $\ln G D P$ in the regression model.

The results reported in the last column of Table 2 show that when occupational gender segregation and region-specific effects are controlled for, $\ln G D P$ increases the male-to-female BMI gap only in countries where more men than women work in physically demanding occupations. This result offers convincing support for the hypothesis of a reduction in the energy requirement at work. We do not observe this effect for physically non-demanding occupations, implying a limited reduction in the energy requirement for these occupations. Overall, the results of the cross-country regressions suggest that the weakening occupational gender segregation hypothesis and the reduction in work intensity hypothesis both contribute to the gender BMI puzzle, but no support is found for the increasing female labor force participation rate hypothesis.

\section{Conclusion}

Women have a lower BMI than men do in high-income countries, and the opposite is true in low-income countries. Consistent with this phenomenon, the BMI of adult women in Japan has decreased consistently since the 1950 s in contrast to a steady increase in men. Using 
Japanese microdata, we studied how changes in energy intake and energy expenditure account for the gender difference in BMI trends. Our findings are as follows. Among adults, both energy intake and energy expenditure have decreased in all gender and age groups. The average male BMI has increased and the average female BMI has decreased because, although the decrease in energy intake was similar between men and women, the decrease in energy expenditure was greater among men than among women. We observe minimal gender differences among children or within cohorts. We find significant differences by occupation in energy expenditure trends but little difference by marital status. These results suggest that the gender differences in BMI and energy expenditure trends are attributed to a greater decrease in physical activity at work among men than among women.

We also conducted a cross-country regression analysis. The results are consistent with the findings from the Japanese data and suggest that women are slimmer than men in more developed countries for two reasons. First, occupational gender segregation has weakened; consequently, a larger number of women now work in physically demanding jobs that have been predominantly held by men. Second, the technological progress associated with economic development has reduced both physically demanding jobs and the energy requirements to perform these jobs. Because physically demanding jobs have traditionally been held predominantly by men, economic development has reduced men's energy expenditure more quickly than that of women. Neither the Japanese NNS analysis nor cross-country analysis provides support for other explanations, such as trends in female labor force participation, marriage market, or early life malnutrition.

Although this paper sheds new light on the dynamics of the relative BMI of men and women, explaining the level and secular trends in BMI is beyond our scope. We have identified energy requirements at work as an important source of the gender BMI gap, but 
determining the main driver behind the global obesity epidemic is a different research question. Additionally, the cause of the declining trend in energy intake in Japan and its generalizability to other countries are left for future research.

Despite these limitations, our analysis emphasizes the importance of paying attention to both energy intake and energy expenditure, which interact with each other and together determine BMI levels and the prevalence of obesity. The decrease in energy requirements at work is ongoing worldwide ( $\mathrm{Ng}$ and Popkin, 2011). The effectiveness of interventions that promote physical exercise to reduce weight remains under debate. Health economics studies have found weight-reduction effects for several interventions for certain subpopulations (Cawley et al., 2007, 2013; Sandy et al., 2013), but some argue that increasing energy expenditure simply results in a matching increase in energy intake (e.g., Luke and Cooper, 2013). Given the small number of past interventions to promote physical activity relative to restricting energy intake and their narrow targeting (e.g., Shemilt et al., 2013), further investigation of the conditions that lead to success is warranted.

Acknowledgments: The authors wish to thank Yukiko Abe, John Cawley, Meliyanni Johar, and Narimasa Kumagai for their helpful comments. Both authors declare that they have no conflicts of interest. Official permission to utilize the National Nutrition Survey (NNS) and the National Health and Nutrition Survey (NHNS) was obtained from the Statistics and Information Department of the Ministry of Health, Labour and Welfare on October 2, 2015 (Permission Number 1002-6) and November 20, 2015 (Permission Number 1120-1), respectively. 
Funding: This work was supported by the Japan Society for the Promotion of Science [Grant-in-Aid for Young Scientists (B) No. 25780187].

\section{References}

Averett, Susan, and Sanders Korenman (1996) "The Economic Reality of the Beauty Myth," Journal of Human Resources, 31(2), 304-330.

Averett, Susan L., Asia Sikora, and Laura M. Argys (2008) "For Better or Worse:

Relationship Status and Body Mass Index," Economics and Human Biology, 6(3), 330-349.

Bleich, Sara N., David Cutler, Christopher Murray, and Alyce Adams (2008) "Why is the Developed World Obese?" Annual Review of Public Health, 29, 273-295.

Brooks, George A., Nancy F. Butte, William M. Rand, Jean-Pierre Flatt, and Benjamin Caballero (2004) "Chronicle of the Institute of Medicine Physical Activity Recommendation: How a Physical Activity Recommendation Came to be among Dietary Recommendations," American Journal of Clinical Nutrition, 79(5), 921S930S.

Case, Anne, and Alicia Menendez (2009) "Sex Differences in Obesity Rates in Poor Countries: Evidence from South Africa," Economics and Human Biology, 7(3), 271-282.

Cawley, John, Chad Meyerhoefer, and David Newhouse (2007) "The Impact of State Physical Education Requirements on Youth Physical Activity and Overweight," Health Economics, 16 (12), 1287-1301.

Cawley, John, David Frisvold, and Chad Meyerhoefer (2013) “The Impact of Physical Education on Obesity among Elementary School Children," Journal of Health Economics, 32 (4), 743-755.

Church, Timothy S., Diana M. Thomas, Catrine Tudor-Locke, Peter T. Katzmarzyk, Conrad P. Earnest, Ruben Q. Rodarte, Corby K. Martin, Steven N. Blair, and Claude Bouchard (2011) "Trends over 5 Decades in U.S. Occupation-Related Physical Activity and their Associations with Obesity," PLOS ONE, 6(5), e19657.

Cutler, David M., Edward L. Glaeser, and Jesse M. Shapiro (2003) "Why Have Americans Become More Obese?” Journal of Economic Perspectives, 17(3), 93-118. 
Dinour, Lauren, May May Leung, Gina Tripicchio, Sahar Khan, and Ming-Chin Yeh (2012)

"The Association between Marital Transitions, Body Mass Index, and Weight: A

Review of the Literature,” Journal of Obesity, 2012, 294974.

Finucane, Mariel M., Gretchen A. Stevens, Melanie J. Cowan, Goodarz Danaei, John K. Lin, Christopher J. Paciorek, Gitanjali M. Singh, Hialy R. Gutierrez, Yuan Lu, Adil N. Bahalim, Farshad Farzadfar, Leanne M. Riley, and Majid Ezzati (2011) "National, Regional, and Global Trends in Body-Mass Index Since 1980: Systematic Analysis of Health Examination Surveys and Epidemiological Studies with 960 Country-Years and 9.1 Million Participants," Lancet, 377(9765), 557-567.

Fisman, Raymond, Sheena S. Iyengar, Emir Kamenica, and Itamar Simonson (2006) "Gender Differences in Mate Selection: Evidence From a Speed Dating Experiment," Quarterly Journal of Economics, 121(2), 673-697.

Flegal, Katherine M., Margaret D. Carroll, Cynthia L. Ogden, and Lester R. Curtin (2010) "Prevalence and Trends in Obesity among US Adults, 1999-2008," JAMA, 303(3), $235-41$

Frisco, Michelle L., Adam M. Lippert, and Margaret M. Weden (2012) "The Multidimensional Relationship between Early Adult Body Weight and Women's Childbearing Experience," Social Science \& Medicine, 74(11), 1703-1711.

Funatogawa, Ikuko, Takeshi Funatogawa, Mutsuhiro Nakao, Kanae Karita, and Eiji Yano (2009) "Changes in Body Mass Index by Birth Cohort in Japanese Adults: Results from the National Nutrition Survey of Japan 1956-2005," International Journal of Epidemiology, 38(2), 83-92.

Ganpule, A.A., S. Tanaka, K. Ishikawa-Takata, and I. Tabata (2007) "Interindividual Variability in Sleeping Metabolic Rate in Japanese Subjects," European Journal of Clinical Nutrition, 61(11), 1256-1261.

Godard, Mathilde (2016) "Gaining Weight through Retirement? Results from the SHARE Survey," Journal of Health Economics, 45(1), 27-46.

Goldberg, G.R., A.E. Black, S.A. Jebb, T.J. Cole, P.R. Murgatroyd, W.A. Coward, and A.M. Prentice (1991) “Critical Evaluation of Energy Intake Data Using Fundamental Principles of Energy Physiology: 1. Derivation of Cut-Off Limits to Identify Under-Recording," European Journal of Clinical Nutrition, 45(12), 569-581. 
Jéquier, Eric, and Luc Tappy (1999) "Regulation of Body Weight in Humans," Physiological Reviews, 79(2), 451-480.

Kagawa, Masaharu, Yasuaki Tahara, Kazuhiko Moji, Rieko Nakao, Kiyoshi Aoyagi, and Andrew P. Hills (2011) "Secular Changes in Growth among Japanese Children Over 100 Years (1900-2000)" Asia Pacific Journal of Clinical Nutrition, 20(2), 180-189.

Katzmarzyk, Peter T. (2008) "Obesity and Physical Activity among Aboriginal Canadians," Obesity, 16(1), 184-190.

Lakdawalla, Darius, and Tomas Philipson (2007) "Labor Supply and Weight," Journal of Human Resources, 42(1), 85-116.

Lakdawalla, Darius, and Tomas Philipson (2009) "The Growth of Obesity and Technological Change," Economics and Human Biology, 7, 283-293.

Luke, Amy, and Richard S. Cooper (2013) "Physical Activity Does Not Influence Obesity Risk: Time to Clarify the Public Health Message," International Journal of Epidemiology, 42, 1848-1851.

Maruyama, Shiko, and Sayaka Nakamura (2015) “The Decline in BMI among Japanese Women after World War II," Economics and Human Biology, 18, 125-138.

Michaud, Pierre-Carl, Arthur H.O. van Soest, and Tatiana Andreyeva (2007) “Cross-Country Variation in Obesity Patterns among Older Americans and Europeans," Forum for Health Economics \& Policy, 10(2), ISSN (Online) 1558-9544, DOI: https://doi.org/10.2202/1558-9544.1087.

Millward, D. Joe (2013) "Energy Balance and Obesity: A UK Perspective on the Gluttony v. Sloth Debate," Nutritional Research Review, 26(2):89-109.

Molnár, Dénes, Sára Jeges, Eva Erhardt, and Yves Schutz (1995) "Measured and Predicted Resting Metabolic Rate in Obese and Nonobese Adolescents." Journal of Pediatrics, 127(4), 571-577.

Mukhopadhyay, Sankar (2008) "Do Women Value Marriage More? The Effect of Obesity on Cohabitation and Marriage in the USA," Review of Economics of the Household, 6(2), 111-126.

Ng, S.W., and B.M. Popkin (2012) “Time Use and Physical Activity: A Shift Away from Movement across the Globe," Obesity Reviews, 13(8), 659-80.

Numajiri, Kokichi (1979) Energy Metabolism of Activity. Kawasaki: The Institute for Science of Labour (in Japanese). 
OECD (2012) Closing the Gender Gap: Act Now.

http://www.oecd.org/inclusive-growth/Closing\%20the\%20Gender\%20Gaps.pdf

Robinson, Whitney R. (2012) “Gender-Specific Effects of Early Nutritional Restriction on

Adult Obesity Risk: Evidence from Quasi-Experimental Studies,” Obesity, 20(12), 2464-2466.

Ruhm, Christopher J. (2012) "Understanding Overeating and Obesity," Journal of Health Economics, 31(6), 781-796.

Sandy, Robert, Rusty Tchernis, Jeffrey Wilson, Gilbert Liu, Xilin Zhou (2013) "Effects of the Built Environment on Childhood Obesity: The Case of Urban Recreational Trails and Crime," Economics \& Human Biology, 11, 18-29.

Sarma, Sisira, Gregory S. Zaric, M. Karen Campbell, and Jason Gilliland (2014) "The Effect of Physical Activity on Adult Obesity: Evidence from the Canadian NPHS Panel," Economics \& Human Biology, 14, 1-21.

Shemilt, Ian, Gareth J. Hollands, Theresa M. Marteau, Ryota Nakamura, Susan A. Jebb, Michael P. Kelly, Marc Suhrcke, and David Ogilvie (2013) "Economic Instruments for Population Diet and Physical Activity Behaviour Change: A Systematic Scoping Review," PLoS ONE, 8(9): e75070. doi:10.1371/journal.pone.0075070

Smil, Vaclav, and Kazuhiko Kobayashi (2012) Japan's Dietary Transition and Its Impact. Cambridge, MA: The MIT Press.

Swami, Viren (2006) "The Influence of Body Weight and Shape in Determining Female and Male Physical Attractiveness." Chapter 2, in: Kindes, Marlene V., (ed.) Body Image: New Research. Nova Biomedical Books, New York, USA, pp. 35-61.

Thorburn, A.W. (2005) "Prevalence of Obesity in Australia," Obesity Reviews, 6, 187-189. Wardle, Jane, Jo Waller, and Martin J. Jarvis (2002) "Sex Differences in the Association of Socioeconomic Status with Obesity," American Journal of Public Health, 92(8), 1299-1304.

Wells, Jonathan C.K., Akanksha A. Marphatia, Tim J. Cole, and David McCoy (2012) "Associations of Economic and Gender Inequality with Global Obesity Prevalence: Understanding the Female Excess," Social Science \& Medicine, 75(3), 482-490. Westerterp, Klaas R. (2004) “Diet Induced Thermogenesis,” Nutrition \& Metabolism, 1(1), 5. 
Table 1: Summary Statistics of Cross-Country Data

\begin{tabular}{|c|c|c|c|}
\hline Variable & Definition & Mean & S.D. \\
\hline Male BMI & Mean age-adjusted male BMI & 24.797 & 2.364 \\
\hline Female BMI & Mean age-adjusted female BMI & 25.541 & 2.483 \\
\hline M-F BMI gap & $=$ Male BMI - Female BMI & -0.745 & 1.404 \\
\hline GDP & Per capita GDP in 2008 (2014 US dollars) & 13683 & 15007 \\
\hline $\operatorname{lnGDP}$ & Natural log of per capita GDP, 2008 (2014 US dollars) & 8.843 & 1.283 \\
\hline $\operatorname{lnGDP} 1988$ & Natural log of per capita GDP, 1988 (2014 US dollars) & 8.037 & 1.294 \\
\hline M-F labor gap & $\begin{array}{l}\text { Male-female difference in labor force participation rate of } \\
\text { population aged } 15+\end{array}$ & 0.225 & 0.151 \\
\hline $\begin{array}{l}\text { M-F gap by } \\
\text { occupation }\end{array}$ & $\begin{array}{l}\text { Male-female difference in proportion of working-age population } \\
\text { (age 15-64) employed in each occupational category: }\end{array}$ & & \\
\hline skilled agriculture & skilled agricultural and fishery workers & 0.032 & 0.055 \\
\hline clerk & clerks & -0.022 & 0.034 \\
\hline craft & craft and related trades workers & 0.094 & 0.056 \\
\hline elementary & elementary occupations & 0.018 & 0.052 \\
\hline professional & $\begin{array}{l}\text { legislators, senior officials, managers, professionals, associate } \\
\text { professionals and technicians }\end{array}$ & 0.020 & 0.060 \\
\hline plant \& machine & plant and machine operators and assemblers & 0.060 & 0.033 \\
\hline service \& sales & $\begin{array}{l}\text { service workers, shop and market sales workers, armed forces, } \\
\text { and not otherwise categorized occupations }\end{array}$ & -0.018 & 0.054 \\
\hline $\begin{array}{l}\text { M-F gap }>0 \text { : } \\
\text { physically } \\
\text { demanding }\end{array}$ & $\begin{array}{l}\text { Dummy for positive M-F gap in physically demanding } \\
\text { occupations (skilled agriculture, plant \& machine, and service \& } \\
\text { sales) }\end{array}$ & 0.926 & 0.263 \\
\hline $\begin{array}{l}\text { M-F gap }>0 \text { : } \\
\text { physically not } \\
\text { demanding }\end{array}$ & $\begin{array}{l}\text { Dummy for positive M-F gap in physically non-demanding } \\
\text { occupations (all the other categories than skilled agriculture, plant } \\
\& \text { machine, and service \& sales) }\end{array}$ & 0.943 & 0.233 \\
\hline America & Dummy for America (reference group) & 0.171 & 0.378 \\
\hline Africa & Dummy for Africa & 0.291 & 0.456 \\
\hline Asia & Dummy for Asia & 0.269 & 0.444 \\
\hline Europe & Dummy for Europe & 0.223 & 0.417 \\
\hline Oceania & Dummy for Oceania & 0.046 & 0.209 \\
\hline
\end{tabular}

Notes: $N=175$. Due to missing values, the number of observations is 133 for $\ln G D P 1988$ and 102 for occupation-related variables. 
Table 2: Cross-Country Regression of Male-to-Female Difference in BMI

\begin{tabular}{|c|c|c|c|c|c|c|}
\hline Variable & Model 1 & Model 2 & Model 3 & Model 3a & Model 4 & Model 5 \\
\hline $\operatorname{lnGDP}$ & $\begin{array}{c}0.439 * * * \\
(0.118)\end{array}$ & $\begin{array}{c}0.434 * * * \\
(0.125)\end{array}$ & $\begin{array}{l}-0.000 \\
(0.141)\end{array}$ & $\begin{array}{c}0.290 \\
(0.181)\end{array}$ & $\begin{array}{l}0.218 \\
(0.284)\end{array}$ & $\begin{array}{c}0.035 \\
(0.702)\end{array}$ \\
\hline $\begin{array}{l}\operatorname{lnGDP} * \text { (M-F gap }>0: \\
\text { physically demanding) }\end{array}$ & & & & & & $\begin{array}{c}0.514 * * * \\
(0.187)\end{array}$ \\
\hline $\begin{array}{l}\operatorname{lnGDP} *(\mathrm{M}-\mathrm{F} \text { gap }>0 \text { : } \\
\text { physically not demanding })\end{array}$ & & & & & & $\begin{array}{l}-0.265 \\
(0.711)\end{array}$ \\
\hline $\operatorname{lnGDP} 1988$ & $\begin{array}{l}-0.013 \\
(0.140)\end{array}$ & $\begin{array}{l}0.033 \\
(0.144)\end{array}$ & $\begin{array}{c}0.093 \\
(0.124)\end{array}$ & & & \\
\hline M-F labor gap & & $\begin{array}{c}-2.808 * * * \\
(0.608)\end{array}$ & $\begin{array}{c}-2.027 * * * \\
(0.565)\end{array}$ & $\begin{array}{l}-1.835^{*} \\
(0.984)\end{array}$ & & \\
\hline $\begin{array}{l}\text { M-F gap: skilled } \\
\text { agriculture }\end{array}$ & & & & & $\begin{array}{c}-4.561^{* *} \\
(2.089)\end{array}$ & \\
\hline M-F gap: clerk & & & & & $\begin{array}{c}0.564 \\
(5.356)\end{array}$ & \\
\hline M-F gap: craft & & & & & $\begin{array}{l}3.688 \\
(2.400)\end{array}$ & \\
\hline M-F gap: elementary & & & & & $\begin{array}{l}-3.164 \\
(2.278)\end{array}$ & \\
\hline M-F gap: professional & & & & & $\begin{array}{c}3.591 \\
(2.491)\end{array}$ & \\
\hline M-F gap: plant \& machine & & & & & $\begin{array}{l}-7.775^{*} \\
(4.398)\end{array}$ & \\
\hline M-F gap: service $\&$ sales & & & & & $\begin{array}{l}-5.645^{*} \\
(2.898)\end{array}$ & \\
\hline $\begin{array}{l}\text { M-F gap }>0 \text { : physically } \\
\text { demanding }\end{array}$ & & & & & & $\begin{array}{c}-5.354 * * * \\
(1.778)\end{array}$ \\
\hline $\begin{array}{l}\text { M-F gap }>0 \text { : physically not } \\
\text { demanding }\end{array}$ & & & & & & $\begin{array}{c}3.369 \\
(6.633)\end{array}$ \\
\hline Africa & & & $\begin{array}{l}-0.156 \\
(0.316)\end{array}$ & $\begin{array}{l}-0.318 \\
(0.627)\end{array}$ & $\begin{array}{l}-0.537 \\
(0.665)\end{array}$ & $\begin{array}{l}-0.284 \\
(0.634)\end{array}$ \\
\hline Asia & & & $\begin{array}{c}0.858^{* * *} \\
(0.237)\end{array}$ & $\begin{array}{l}0.570^{*} \\
(0.299)\end{array}$ & $\begin{array}{l}0.570^{*} \\
(0.314)\end{array}$ & $\begin{array}{c}0.480 \\
(0.319)\end{array}$ \\
\hline Europe & & & $\begin{array}{c}2.014 * * * \\
(0.274)\end{array}$ & $\begin{array}{c}1.663 * * * \\
(0.366)\end{array}$ & $\begin{array}{c}1.422 * * * \\
(0.417)\end{array}$ & $\begin{array}{c}1.984 * * * \\
(0.321)\end{array}$ \\
\hline Oceania & & & $\begin{array}{l}-0.281 \\
(0.486)\end{array}$ & $\begin{array}{c}0.186 \\
(0.987)\end{array}$ & $\begin{array}{c}0.525 \\
(0.664)\end{array}$ & $\begin{array}{c}0.698 \\
(0.747)\end{array}$ \\
\hline$N$ & 175 & 175 & 175 & 102 & 102 & 102 \\
\hline Adjusted $R^{2}$ & 0.139 & 0.226 & 0.435 & 0.452 & 0.509 & 0.483 \\
\hline
\end{tabular}

Notes: Standard errors robust to heteroskedasticity are reported in the parentheses. All models include a constant, and Models 1 to 3 include an indicator for missing $\ln G D P 1988$.

${ }^{*} \mathrm{p}<0.10,{ }^{* *} \mathrm{p}<0.05,{ }^{* * *} \mathrm{p}<0.01$ 
Figure 1: Mean Age-Adjusted BMI in 2008 by Gender for Selected Countries

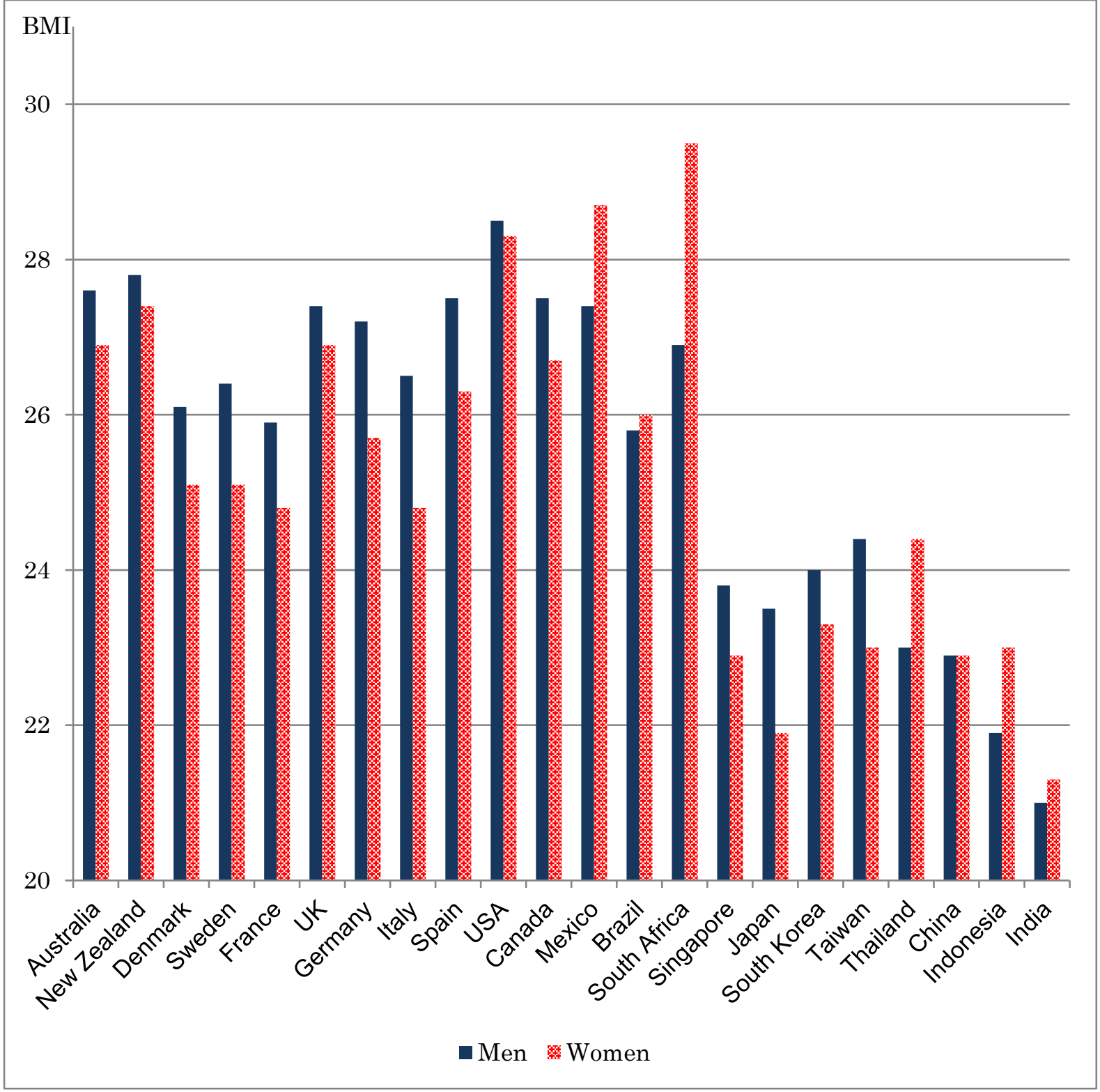

Notes: The countries are ordered by region: Oceania, Europe, America, Africa, and Asia. Within each region, they are ordered in 2008 GDP per capita taken from the IMF's World Economic Outlook database, October 2017 edition. The BMI data are from the Web appendix to Finucane et al. (2011). 
Figure 2: Japanese Trends in Height, Weight, and BMI by Gender and Age Group
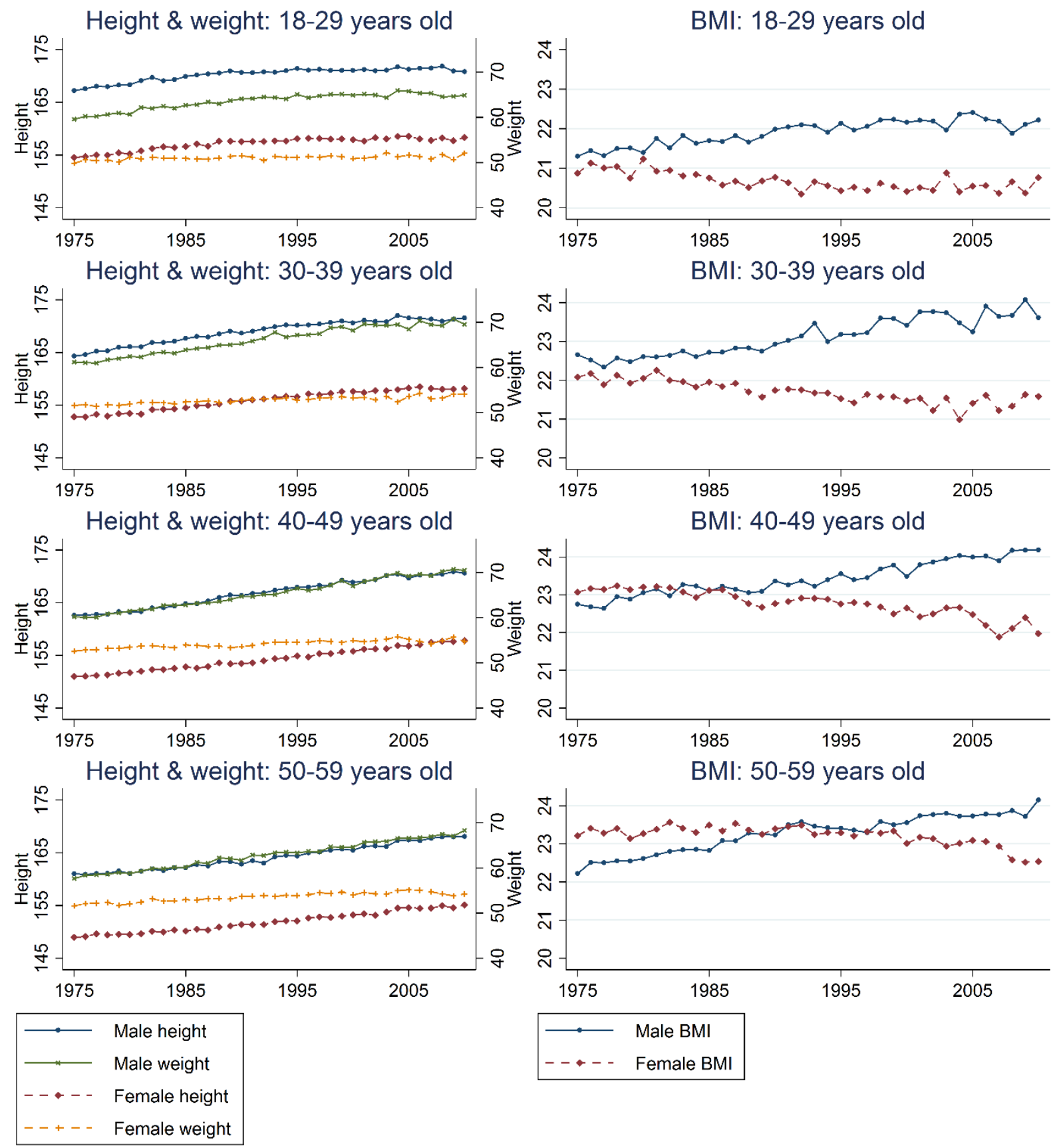

Notes: Height and weight are measured in centimeter and kilogram, respectively. 
Figure 3: Illustration of Steady-State Weight

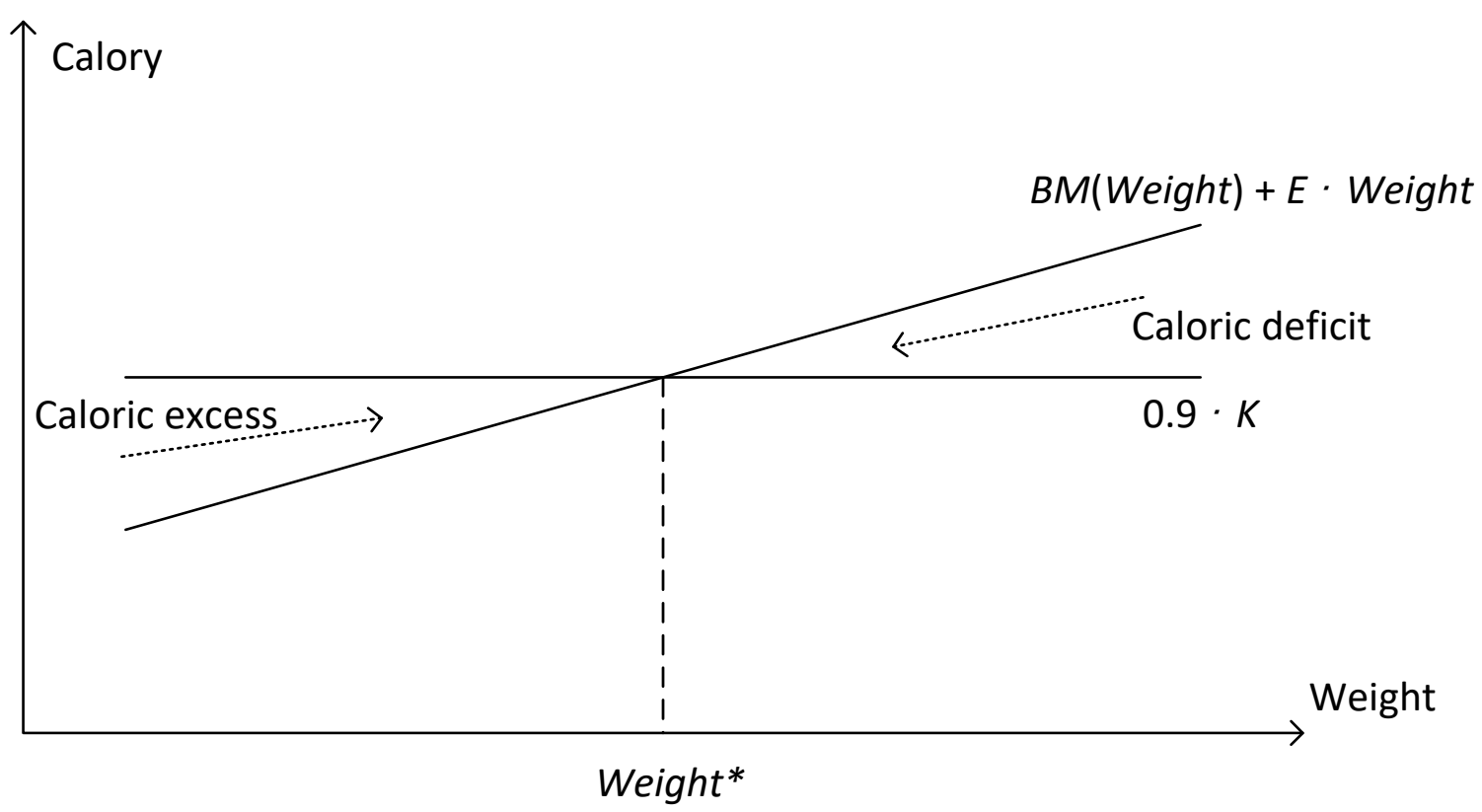

Notes: $E$ is an index of the physical activity level, and $K$ is the daily energy intake.

$B M($ Weight $)$ denotes the daily basal metabolic rate, which is an increasing function of body weight, Weight. Weight ${ }^{*}$ refers to the steady-state weight for given levels of $E$ and $K$. 
Figure 4: Japanese Trends in BMI, $E$, and $K$ by Gender and Age
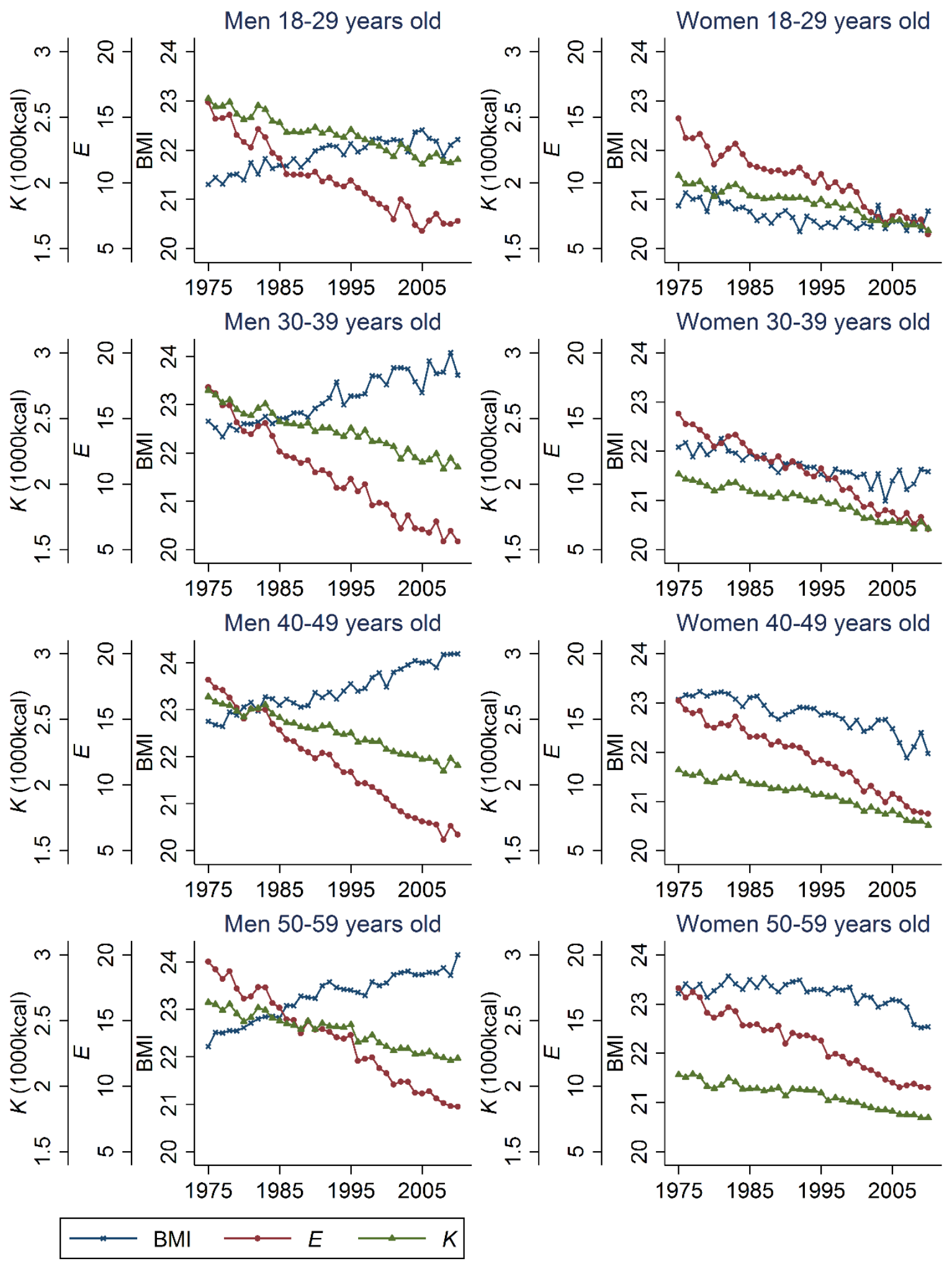

Notes: $E$ is an index of the physical activity level, and $K$ is the daily energy intake. 
Figure 5: Decomposing the Gender Gap in the BMI Trend

18-29 years old
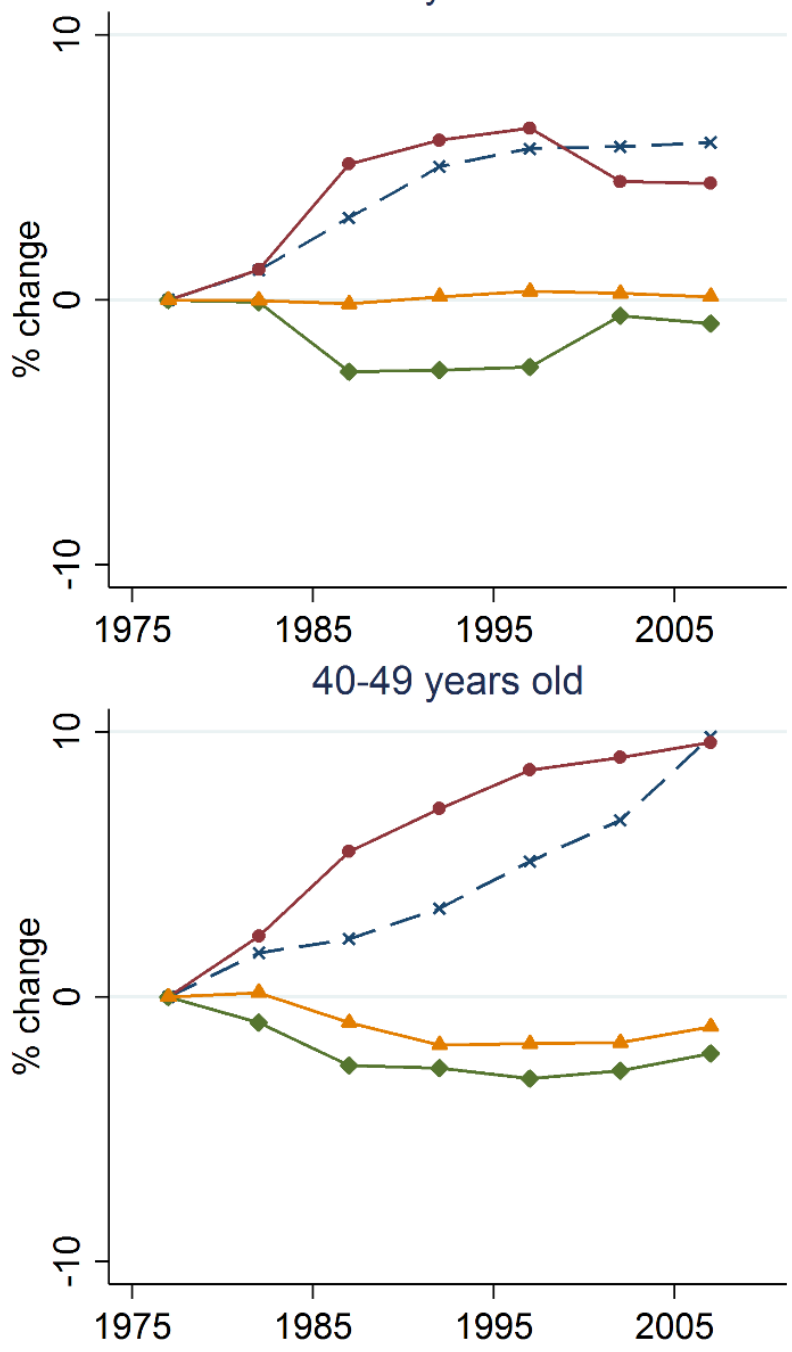

- $*$ M-F difference in \% change in BMI

$\longrightarrow$ M-F difference in Es contribution

M-F difference in $K$ 's contribution

$\longrightarrow \quad M-F$ difference in Height's contribution
30-39 years old
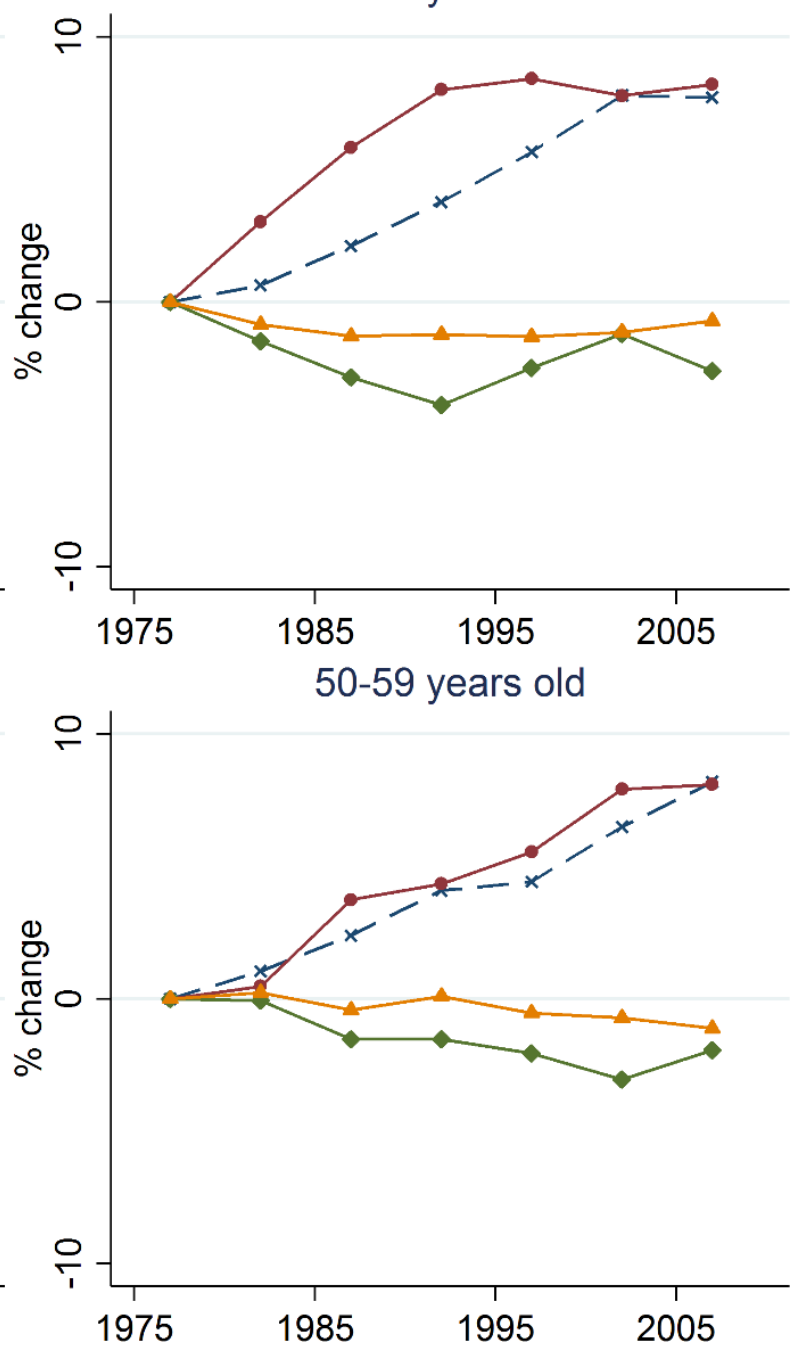

Notes: $E$ is an index of the physical activity level, and $K$ is the daily energy intake. The male-female difference in contributions refers to the male-female difference in cumulative percentage change in the contributions of $E, K$, and height relative to the base period, 1975-1979. The male-female difference in percentage change in BMI is adjusted for the change in mean age. 
Figure 6: Trends in BMI, $E$, and $K$ among Children and among the 1940s Cohort

Panel A: Children
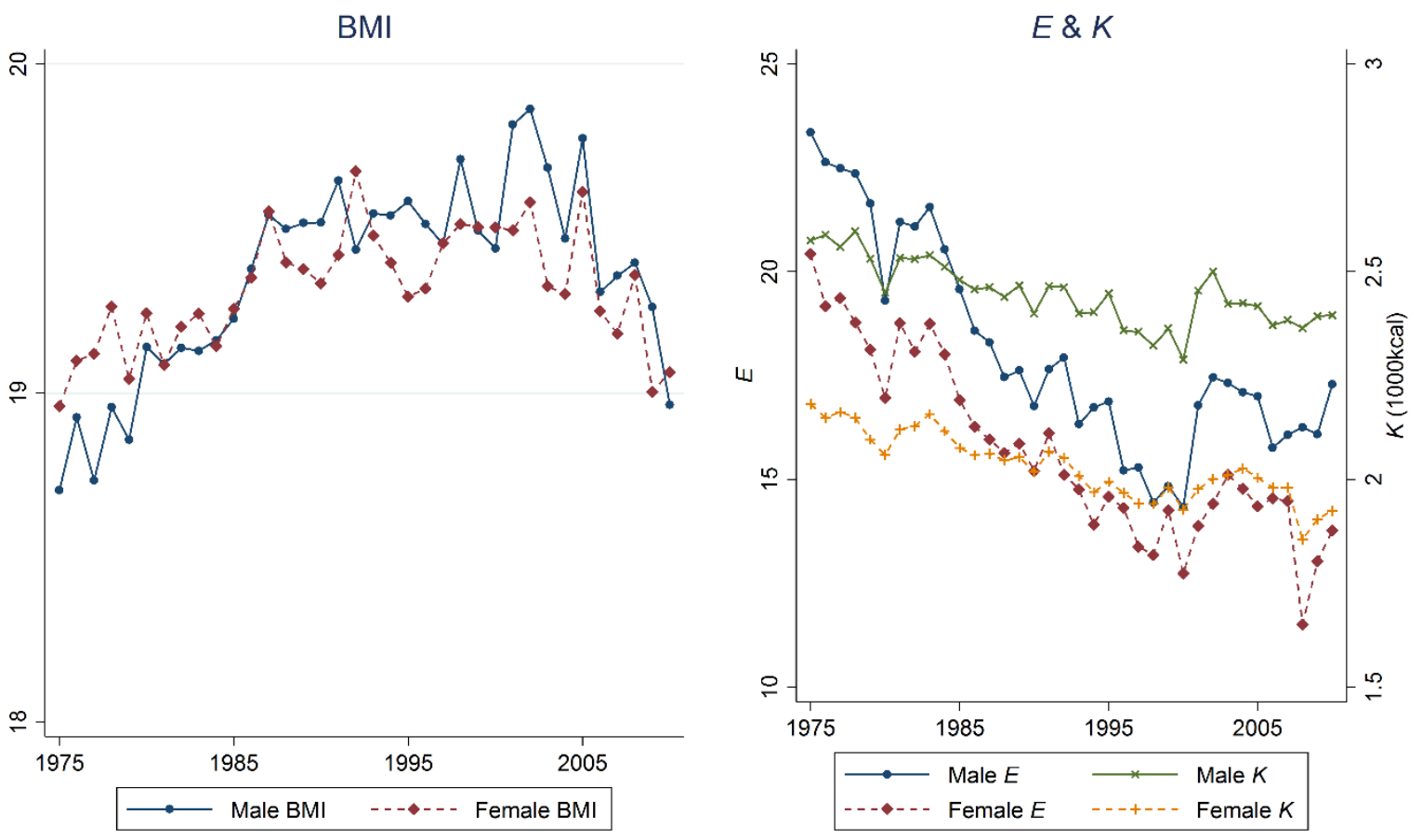

Panel B: 1940s cohort
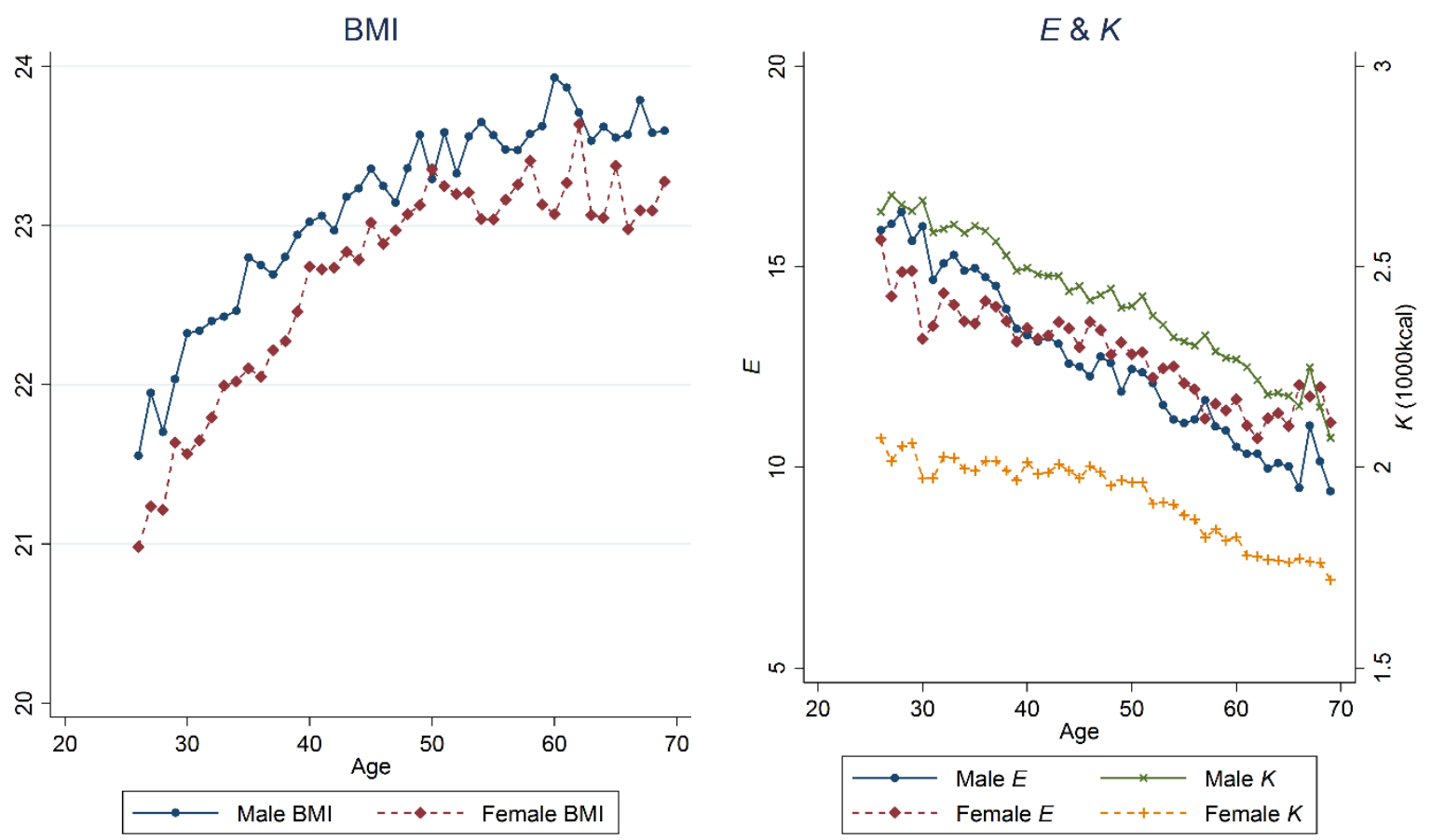

Notes: $E$ is an index of the physical activity level, and $K$ is the daily energy intake. 
Figure 7: Comparison by Marital Status
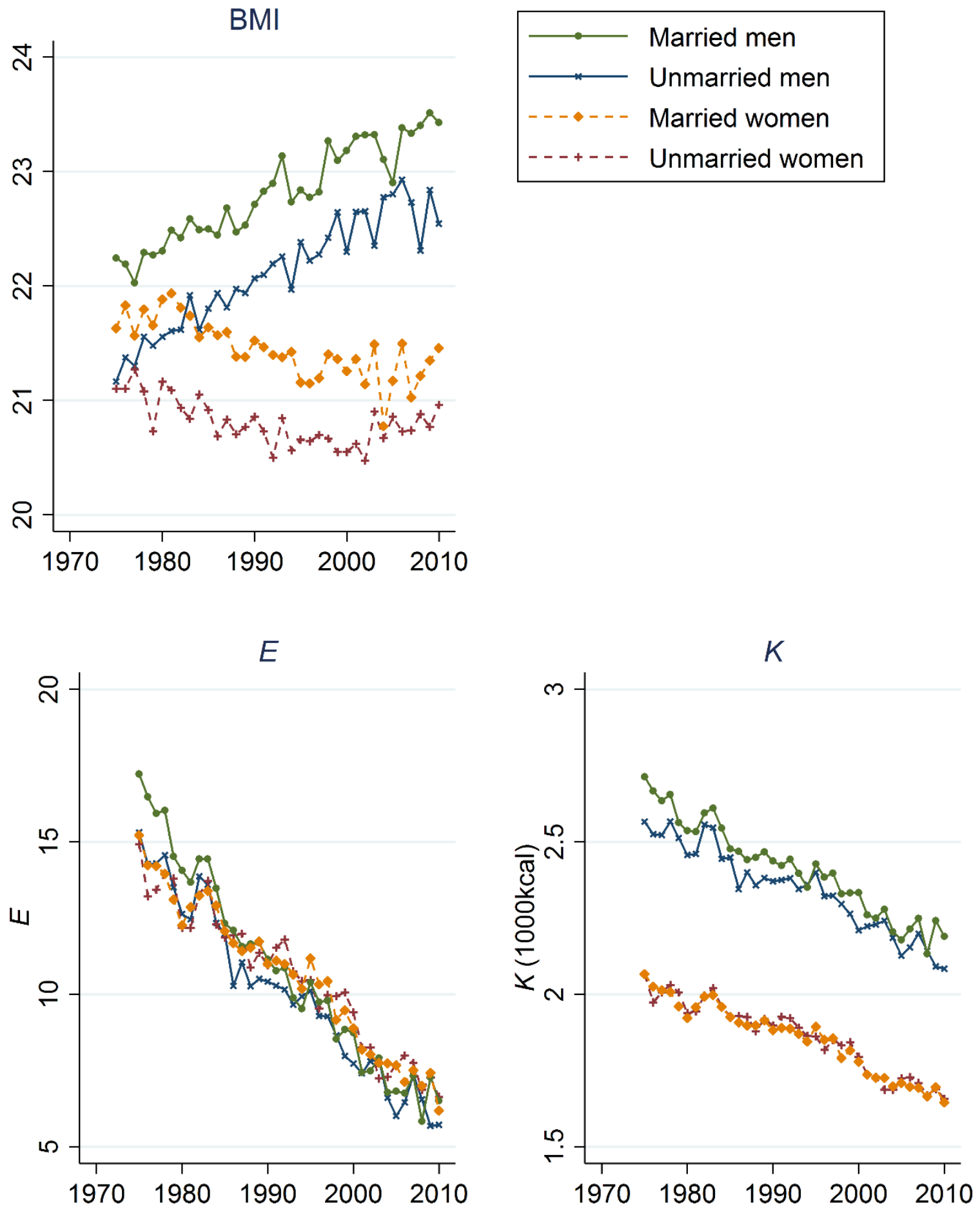

Notes: Based on individuals aged 18-39. $E$ is an index of the physical activity level, and $K$ is the daily energy intake. 
Figure 8: Comparison by Occupation
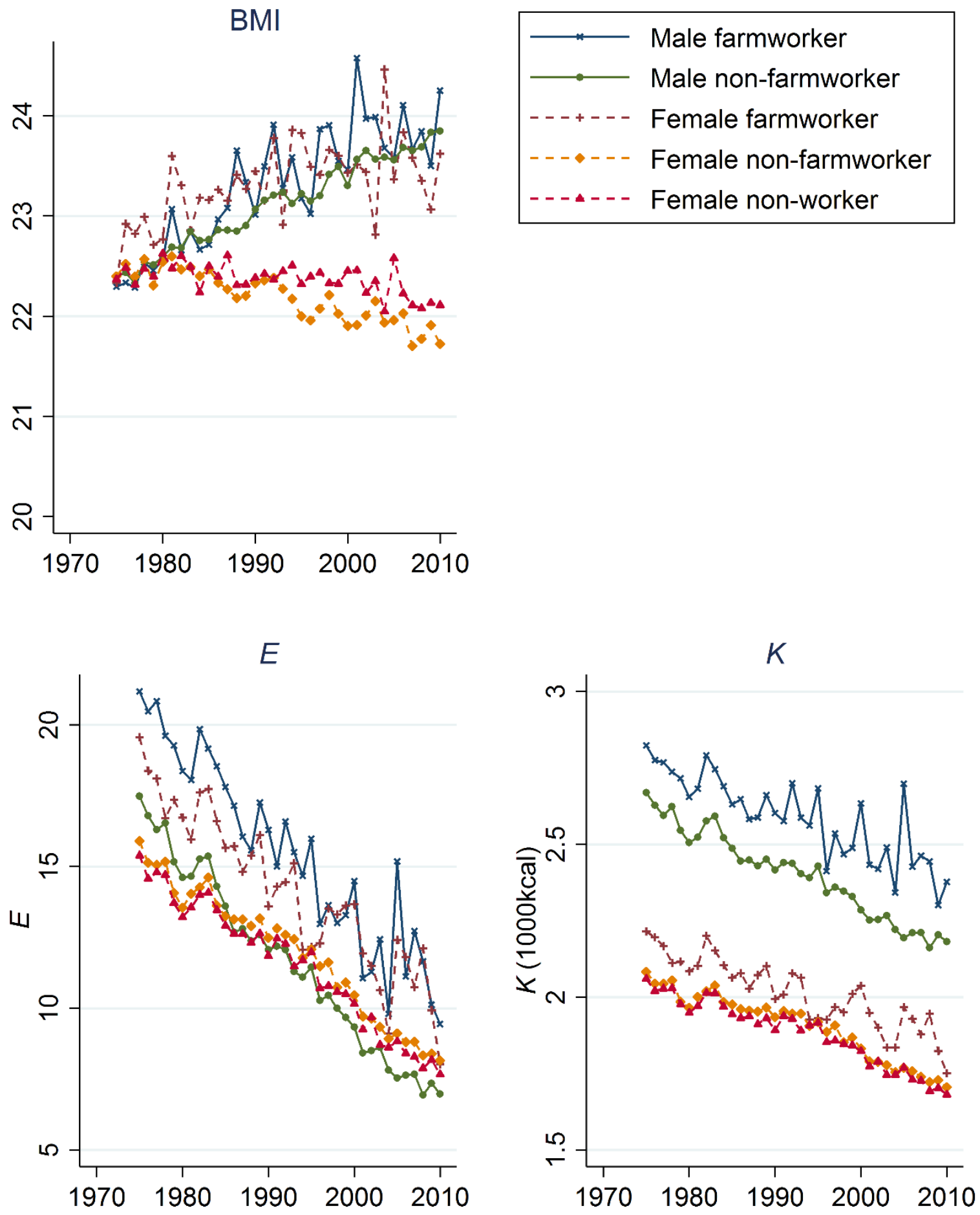

Notes: Based on individuals aged 22-59. $E$ is an index of the physical activity level, and $K$ is the daily energy intake. 


\title{
Supplementary Document to:
}

\section{Why Are Women Slimmer Than Men in Developed Countries?}

\section{Appendix 1. Details of Data Construction for the Analysis of Japanese Data}

\author{
The National Nutrition Survey
}

We used individual-level data drawn from the 1975-2010 National Nutrition Survey (NNS), a nationally representative, annual, cross-sectional survey conducted by the Ministry of Health, Labour and Welfare. The survey is conducted in November of each year and assesses the health and nutritional status of Japanese individuals aged one year and older. The target areas are cluster sampled from all 47 Japanese prefectures, and all households within the sampled areas are asked to participate in the survey. The survey's response rates are not reported at the individual level, but in 2010, for instance, approximately $69 \%$ of the invited households participated in the survey. The sample size varies from year to year. In 1975, the sample size was approximately 22,000 individuals, but by 2010 , it had decreased to 8,815 individuals. Further details of the NNS are described elsewhere (Katanoda and Matsumura, 2002; Katanoda et al., 2005). We did not use surveys prior to 1975 due to the lack of micro data.

\section{Missing observations and outliers}

Height and weight values were missing for $18.6 \%$ of the sample. We manually excluded outliers based on the sample distribution. The outliers that were excluded were: men with a height of less than $130 \mathrm{~cm}$, a weight of less than $25 \mathrm{~kg}$, or a BMI greater than 50 ; women with a height of less than $120 \mathrm{~cm}$, a weight of less than $20 \mathrm{~kg}$, or a BMI greater than 60; and individuals with an energy intake of zero or exceeding 10,000 kcal. This data cleaning reduced the sample size by approximately $0.8 \%$. 


\section{The Goldberg cutoff}

The Goldberg cutoff tests the validity of food intake data by comparing energy intakes with the predicted energy expenditure required for a given level of physical activity. An energy intake value is classified as implausible if it is smaller/larger by two standard deviations than the mean of the predicted energy expenditure. The NNS estimates the required energy expenditure of individuals for 2005-2009 based on a questionnaire on physical activity, so our sample was taken from this period. We derived the standard deviation based on Black (2000) and predicted basal metabolism based on Ganpule et al. (2007). For light, medium, and heavy physical activity levels, the minimum cutoff values of the energy intake to basal metabolism ratio were $0.788,0.900$, and 1.069 , respectively, and the maximum cut-off values were $2.843,3.376$, and 3.909, respectively. The results indicate that energy intake was implausibly small for $6.7 \%$ of individuals and implausibly large for $0.2 \%$ of individuals during 2005-2009. Thus, under-reporting of food intake was considerably less prevalent than in similar surveys, including the US National Health and Nutrition Examination Survey (Johnston and Lee, 2011). Consistent with these results, previous studies comparing self-reported energy intake and precisely measured energy expenditure by the doubly labeled water (DLW) method indicate that reporting bias among Japanese respondents is remarkably smaller than the bias found in Western studies (Okubo et al., 2008; Ishikawa-Takata et al., 2011).

\section{Estimation of individual energy and nutrient intake for 1975-1994}

Food records are only available at the individual level from 1995 to 2010; before 1995, only household-level values are available. We, therefore, estimated individual energy intakes for 1975-1994 as follows. First, we calculated energy intake from alcohol and energy intake 
from other sources separately. The NNS records the consumption of sake, beer, and "other liquor." We assumed that the alcohol content by volume was $15 \%$ for sake and $5 \%$ for beer (Ministry of Health, Labour and Welfare 2000). The alcohol content of "other liquor" was assumed to be $9 \%$ based on our analysis of alcohol intake by beverage type reported in the NNS 2003-2010. The energy from one gram of alcohol was assumed to be $7.1 \mathrm{kcal}$. Second, using the 1995-1999 data, we estimated a regression model of individual energy intake separately for each gender. For each person's non-alcoholic energy intake, the logarithm was linearly regressed on age, height, occupation, pregnancy and lactating status, and the type of meal the respondent consumed. We controlled for whether the three meals were skipped, eaten at home, or eaten out, and if eaten out, the type of food: noodles, sushi, a rice bowl, bread, curry, pasta, a school meal, a meal provided at the workplace, other Western food, and other Japanese food. For alcoholic energy intake, a Type-I Tobit model was estimated for each gender with the same set of explanatory variables. Third, based on the estimated regression models, individual energy intake was predicted for the 1975-1994 respondents. Finally, each household's recorded energy intake from 1975 to 1994 was apportioned to each household member in proportion to the predicted individual energy intake. We used this apportioned amount as the estimate of individual energy intake. In the extended analysis of the proportion of energy intake by macronutrient in Appendix 3, individual intakes of fat, carbohydrates, and protein were estimated analogously.

We examined the validity of these individual energy intake estimates in several ways. First, for cross-validation, we applied the same method as above to estimate individual-level energy intake in 1995 based on household-level energy intake data from 1996 to 1999. The correlation coefficient between the estimated and actual individual energy intakes was 0.838 , indicating the accuracy of our approach. Second, we examined whether limiting the sample to 
single-person households changes our results. Because individual energy intake was available for those living alone for the entire study period, a similar result with this restriction provided further support for the use of imputed individual energy intakes. The trends in BMI, $E$, and $K$ by gender and age among single-person households presented in Figure A1 are highly similar to those shown in Figure 2. This finding confirms that our results are not driven by the estimation of individual energy intakes. Third, we estimated individual non-alcoholic energy intakes as a weighted sum of the apportioned values of protein, carbohydrates, and fat and compared them with the apportioned value of non-alcoholic energy intake described above. These two methods yielded highly similar estimates; the correlation coefficient between the two estimates was 0.982 .

Prediction of basal metabolism (BM) based on Ganpule et al. (2007)

Ganpule et al.'s (2007) original equations contain typographical errors, which are corrected in Miyake et al. (2011). Miyake et al. (2011) find that Ganpule et al.'s (2007) equations provide a better fit for the Japanese population than do other conventional equations used for $B M$ prediction.

Applying the steady-state model for children

The estimation of $E$ for children relies on the same steady-state framework as for adults but requires one modification. Ganpule et al.'s (2007) equation to calculate BM is intended for adults. Therefore, to estimate $E$ for children, we used fasting resting energy expenditure (REE) as a proxy for child BM. REE has been commonly used for children as a substitute for BM because whereas BM is measured in the supine position, REE is typically measured in the sitting position. A recent study found a significant difference between BM 
and fasting REE (Miles-Chan et al., 2014). To predict the fasting REE for children aged 10-17 from height, weight, age, and gender, we used Molnár et al.'s (1995) estimates. Molnár et al.'s (1995) equation is based on Hungarian subjects aged 10-16, but it provides a good fit for Japanese children in the same age group (Kaneko et al., 2013). Assuming that fasting REE is equal to BM, Molnár et al.’s (1995) equation implies

$$
\begin{aligned}
& \text { Boys' BM }(\mathrm{kcal} / \mathrm{d})=(50.9 * W+25.3 * H-50.3 * A+26.9) / 4.1868, \\
& \text { Girls' BM }(\mathrm{kcal} / \mathrm{d})=(51.2 * W+24.5 * H-207.5 * A+1629.8) / 4.1868 .
\end{aligned}
$$

\section{Appendix 2. Unbiasedness of the Aggregate Mean of $E$}

We used the steady-state assumption as an approximation to obtain aggregate levels of energy expenditure. At the individual level, each of the observed data points may deviate from the steady-state values for two reasons. First, observed individual energy intake might contain non-negligible daily variations even if the individual is in a steady state (Black, 2000). In the NNS, like many similar surveys, energy intake is obtained from food records covering a short period of time (three consecutive days from 1975 to 1994 and one day since 1995), although the NNS instructs participating households to choose a survey period during which household members eat their usual meals and to avoid holidays and special occasions. Second, some individuals may be in the process of transitioning to a new steady state and thus may have a non-negligible energy imbalance. Examples of such changes include a reduction in energy intake for dieting and changes in energy requirements at work due to a job change. According to Hall et al. (2011), it takes approximately two years for bodyweight to respond to a change in energy intake. 
However, the aggregate cell mean of $E$ by age and gender is unbiased as long as $K$ 's deviation from the steady-state level is distributed with a mean of zero. Formally, equation (1) can be rewritten as

$$
E=\left(0 \cdot 9 \cdot K-B M\left(\text { Age, Height, Weight }{ }^{*}\right)\right) / \text { Weight }{ }^{*}
$$

Because $E$ is linear in $K$, measurement error in $K$ does not cause either bias or inconsistency to the aggregate mean of $E$ if the measurement error has a zero mean. Suppose an energy imbalance exists, and instead of (A3) we have

$$
K=B M(\text { Age, Height }, \text { Weight })+E \cdot \text { Weight }+0 \cdot 1 \cdot K+e,
$$

where $e \neq 0$. Then, we have

$$
E=(0 \cdot 9 \cdot K-B M(\text { Age, Height, Weight })-e) / \text { Weight }
$$

Again, because $E$ is linear in $e$, fluctuations in $e$ do not cause either bias or inconsistency to the aggregate mean of $E$ if $e$ has a zero mean and is orthogonal to the distribution of Weight.

\section{Appendix 3. Details of Decomposition Results}

Numerical results for the full sample

Table A1 reports the results of the decomposition analysis of the change in BMI between the two periods, 1975-1979 and 2001-2010. Based on Equation (5), percentage changes in BMI were decomposed to the contributions of energy intake, energy expenditure, and height, as shown in the rightmost three columns. Because a decrease in $E$ leads to a higher BMI and a decrease in $K$ and an increase in Height lead to a lower BMI, E's contribution is positive, and $K$ and Height's contributions are negative in every gender and age group.

\section{Decomposition by occupation}


Decomposition results by occupation with age adjustment are shown in Figure A2. The contribution of changes in mean age was subtracted from the male-female difference in the percentage changes in BMI. The upper-left panel shows that among farmworkers, the male-female BMI difference is small for the age-adjusted change rate, and the contribution of $E$ does not explain the male-female BMI difference. This finding is in contrast to the next two panels, which show patterns consistent with the full sample results discussed earlier. The upper-right panel shows that the increasing gender difference in BMI is driven by the gender difference in the $E$ trend (a faster reduction in $E$ among male non-farmworkers than among female non-farmworkers). A similar pattern is found in the lower-left panel, which decomposes the gender difference in the BMI trend between male non-farmworkers and female non-workers.

\section{Appendix 4. Possible Explanations for Differential BMI Trends}

In our decomposition analysis, we find that the gender difference in the BMI trend is attributed to the greater reduction in energy expenditure among men than among women. Nevertheless, it is worthwhile to examine whether the gender BMI puzzle in Japan can be explained by alternative hypotheses proposed in the literature. This is especially important because our decomposition analysis relies on several assumptions, including the steady-state framework, and because our decomposition analysis does not specify the underlying causes of those changes. In this Appendix, we discuss other potential explanations and argue that they cannot explain the gender difference in the BMI trend in Japan.

Trends in energy intake, energy supply, and food price 
Previous studies have attributed the growth in obesity to the increase in energy supply (Cutler et al., 2003; Bleich et al., 2008; Swinburn et al., 2009, 2011). Figure A3 compares the trend in per capita energy intake from 1960 to 2010 in Japan obtained from the NNS with the trends in per capita energy supply and relative food price obtained from other data sources. The relative food price is defined as the 2005 food price index divided by the 2005 consumer price index. Figure A3 shows that energy supply and energy intake have followed remarkably different trends. There is no obvious relationship between relative food price and energy supply, in contrast to the conventional view that a growing energy supply has increased energy intake through a reduction in food price (Bleich et al., 2008). Hence, an increase in food supply and a reduction in food price cannot explain the gender BMI puzzle in Japan.

Trends in the proportion of dietary composition

Randomized control trials have found significant weight-reducing effects of low glycemic index diets and high protein diets over short periods (Livesey et al. 2008; Wycherley et al. 2012). As shown in Figure A4, however, increasing trends in the proportion of dietary fat have been almost parallel across gender and age groups, rejecting the relevance of a high-fat diet to the gender BMI puzzle in Japan. This conclusion does not change if we replicate Figure A4 for carbohydrate or protein intake. This finding is consistent with recent systematic review articles that find that neither macronutrient composition nor the glycemic index value of diets is an important predictor of long-term weight changes (Fogelholm et al., 2012; Schwingshackl and Hoffman, 2013; Clifton et al., 2014; Johnston et al., 2014).

Riera-Crichton and Tefft (2014) find a positive long-term association between an increase in carbohydrate intake and obesity growth when controlling for total caloric intake. However, 
their analysis is based on aggregate national data, and the use of food supply as a proxy for food intake suffers from the same concerns as discussed earlier.

\section{Trends in eating behavior}

The increase in snacking frequency is concurrent with a large increase in energy intake and obesity in the US (Cutler et al., 2003). The literature also indicates that the frequency and timing of eating might affect body weight via channels other than energy balance (Mesas et al., 2012). Figure A5 shows that the percentage of Japanese adults who eat between meals also increased across gender and age groups. Figure A6 reports the trend of the percentage of breakfast skipped by the NNS respondents during the survey period, showing stable trends for women and older men and a hump-shaped path for young men. Neither of these figures provides a direct link to the gender BMI puzzle.

\section{Trends in smoking}

Smoking influences body weight through various pathways: smoking reduces appetite and energy intake, increases metabolism and energy expenditure (Chiolero et al., 2008), impairs respiratory functions, and reduces physical activity (Kaczynski et al., 2008). Although smoking cessation is associated with subsequent weight gain in the short term (Chiolero et al., 2008; Pieroni and Salmasi, 2016), the long-term effect appears small (Robertson et al., 2014), and findings on the causal effect of smoking on body weight are mixed (Rashad, 2006; Fang et al., 2009; Wehby et al., 2012; Pieroni and Salmasi, 2015). In Japan, as Figure A7 shows, whereas men's smoking has steadily decreased, women's smoking does not show a strong trend over time. Thus, although a reduction in smoking 
among men is concurrent with the rise in the average male BMI, the trend in smoking cannot explain the continuous decline in the average female BMI.

\section{Trends in sleep duration}

The decline in sleep duration may contribute to the increase in body weight in developed countries because sleep loss may cause feelings of fatigue (reducing physical activity), promote appetite (increasing energy intake), and lower body temperature (reducing energy expenditure through thermoregulation) (Patel and Hu, 2008). As shown in Figure A8, trends in sleep duration in Japan vary across age groups, but there is no gender difference that can explain the gender BMI puzzle.

\section{Appendix 5. List of countries for the Cross-Country Analysis}

The following 175 countries were included in the estimation of Models 1-3. Superscript

$\dagger$ shows the countries used in the estimation of Models 3a, 4, and 5. Countries without superscripts were not included in the extended models due to missing values.

Afghanistan, Albania ${ }^{\dagger}$, Algeria, Angola, Argentina ${ }^{\dagger}$, Armenia, Australia $^{\dagger}$, Austria $^{\dagger}$, Azerbaijan $^{\dagger}$, Bahamas, Bahrain, Bangladesh, Barbados $^{\dagger}$, Belarus $^{\dagger}$, Belgium $^{\dagger}$, Belize $^{\dagger}$, Benin, Bhutan $^{\dagger}$, Bolivia ${ }^{\dagger}$, Bosnia and Herzegovina, Botswana ${ }^{\dagger}$, Brazil $^{\dagger}$, Brunei, Bulgaria ${ }^{\dagger}$, Burkina Faso, Burundi, Cambodia, Cameroon, Canada ${ }^{\dagger}$, Cape Verde, Central African Republic, Chad, Chile $^{\dagger}$, China, Colombia ${ }^{\dagger}$, Comoros, Congo, Costa Rica ${ }^{\dagger}$, Cote d'Ivoire, Croatia ${ }^{\dagger}$, Cyprus $^{\dagger}$, Czech $^{\dagger}$, Democratic Republic of the Congo, Denmark ${ }^{\dagger}$, Djibouti, Dominican Republic ${ }^{\dagger}$, Ecuador $^{\dagger}$, Egypt $^{\dagger}$, El Salvador ${ }^{\dagger}$, Equatorial Guinea, Eritrea, Estonia ${ }^{\dagger}$, Ethiopia $^{\dagger}$, Fiji, Finland $^{\dagger}$, France $^{\dagger}$, Gabon, Gambia, Georgia ${ }^{\dagger}$, Germany $^{\dagger}$, Ghana, Greece ${ }^{\dagger}$, Guatemala, Guinea, Guinea-Bissau, Guyana, Haiti ${ }^{\dagger}$, Honduras, Hong Kong ${ }^{\dagger}$, Hungary ${ }^{\dagger}$, Iceland ${ }^{\dagger}$, India, 
Indonesia $^{\dagger}, \operatorname{Iran}^{\dagger}$, Iraq, Ireland ${ }^{\dagger}$, Israel ${ }^{\dagger}$, Italy $^{\dagger}$, Jamaica $^{\dagger}$, Japan, Jordan ${ }^{\dagger}$, Kazakhstan $^{\dagger}$, Kenya, Kuwait $^{\dagger}$, Kyrgyzstan $^{\dagger}$, Lao, Latvia ${ }^{\dagger}$, Lebanon $^{\dagger}$, Lesotho $^{\dagger}$, Liberia, Libya, Lithuania ${ }^{\dagger}$, Luxembourg $^{\dagger}$, Macedonia ${ }^{\dagger}$, Madagascar $^{\dagger}$, Malawi, Malaysia ${ }^{\dagger}$, Maldives $^{\dagger}$, Mali, Malta $^{\dagger}$, Mauritania, Mauritius ${ }^{\dagger}$, Mexico $^{\dagger}$, Moldova $^{\dagger}$, Mongolia $^{\dagger}$, Montenegro $^{\dagger}$, Morocco $^{\dagger}$, Mozambique, Myanmar, Namibia ${ }^{\dagger}, \mathrm{Nepal}^{\dagger}$, Netherlands ${ }^{\dagger}$, New Zealand ${ }^{\dagger}$, Nicaragua ${ }^{\dagger}$, Niger, Nigeria, Norway ${ }^{\dagger},{\text { Oman, } \text { Pakistan }^{\dagger}, \text { Panama }^{\dagger} \text {, Papua New Guinea, Paraguay }}^{\dagger}$, Peru $^{\dagger}$, Philippines $^{\dagger}$, Poland ${ }^{\dagger}$, Portugal $^{\dagger}$, Qatar $^{\dagger}$, Romania $^{\dagger}$, Russia ${ }^{\dagger}$, Rwanda, Saint Lucia ${ }^{\dagger}$, Saint Vincent and the Grenadines, Samoa, Sao Tome and Principe ${ }^{\dagger}$, Saudi Arabia, Senegal, Serbia ${ }^{\dagger}$, Sierra Leone, Singapore ${ }^{\dagger}$, Slovakia $^{\dagger}$, Slovenia $^{\dagger}$, Solomon Islands, South Africa ${ }^{\dagger}$, South Korea $^{\dagger}$, Spain ${ }^{\dagger}$, Sri Lanka ${ }^{\dagger}$, Sudan, Suriname, Swaziland, Sweden ${ }^{\dagger}$, Switzerland ${ }^{\dagger}$, Syrian $^{\dagger}$, Tajikistan, Tanzania, Thailand ${ }^{\dagger}$, Timor-Leste, Togo, Tonga ${ }^{\dagger}$, Trinidad and Tobago ${ }^{\dagger}$, Tunisia, Turkey $^{\dagger}$, Turkmenistan, UK ${ }^{\dagger}, \mathrm{USA}, \mathrm{Uganda}^{\dagger}, \mathrm{Ukraine}^{\dagger}$, United Arab Emirates ${ }^{\dagger}$, Uruguay ${ }^{\dagger}$, Uzbekistan, Vanuatu, Venezuela, Viet Nam ${ }^{\dagger}$, Yemen, Zambia, Zimbabwe.

\section{References}

Black, A.E. (2000) "Critical Evaluation of Energy Intake Using the Goldberg Cut-Off for Energy Intake: Basal Metabolic Rate. A Practical Guide to its Calculation, Use and Limitations," International Journal of Obesity, 24(9), 1119-1130.

Bleich, Sara N., David Cutler, Christopher Murray, and Alyce Adams (2008) "Why is the Developed World Obese?” Annual Review of Public Health, 29, 273-295.

Chiolero, Arnaud, David Faeh, Fred Paccaud, and Jacques Cornuz (2008) "Consequences of Smoking for Body Weight, Body Fat Distribution, and Insulin Resistance," American Journal of Clinical Nutrition, 87(4), 801-809. 
Clifton, P.M., D. Condo, and J.B. Keogh (2014) "Long Term Weight Maintenance after Advice to Consume Low Carbohydrate, Higher Protein Diets: A Systematic Review and Meta Analysis," Nutrition, Metabolism \& Cardiovascular Diseases, 24(3), 224-35.

Cutler, David M., Edward L. Glaeser, and Jesse M. Shapiro (2003) "Why Have Americans Become More Obese?" Journal of Economic Perspectives, 17(3), 93-118.

Fang, Hai, Mir M. Ali, and John A. Rizzo (2009) "Does Smoking Affect Body Weight and Obesity in China?" Economics and Human Biology, 7(3), 334-350.

Fogelholm, M., S. Anderssen, I. Gunnarsdottir, and M. Lahti-Koski (2012) “Dietary Macronutrients and Food Consumption as Determinants of Long-Term Weight Change in Adult Populations: A Systematic Literature Review," Food \& Nutrition Research, 56, 19103. doi: 10.3402/fnr.v56i0.19103.

Ganpule, A.A., S. Tanaka, K. Ishikawa-Takata, and I. Tabata (2007) “Interindividual Variability in Sleeping Metabolic Rate in Japanese Subjects," European Journal of Clinical Nutrition, 61(11), 1256-1261.

Hall, Kevin D., Gary Sacks, Dhruva Chandramohan, Carson C. Chow, Y. Claire Wang, Steven L. Gortmaker, and Boyd A. Swinburn (2011) "Quantification of the Effect of Energy Imbalance on Bodyweight," Lancet, 378, 826-37.

Ishikawa-Takata, Kazuko, Kyoko Bessyo, Shigeho Tanaka, and Izumi Tabata (2011)

“Accuracy of Energy Intake Estimation by Weighed Dietary Record among Japanese Adults," Japanese Journal of Nutrition and Dietetics, 69(2), 57-66.

Japan Tobacco Inc. (2015) Japan Smoking Rate Survey (in Japanese).

http://www.health-net.or.jp/tobacco/product/pd090000.html. Accessed April 12, 2015. 
Johnston, David W., and Wang-Sheng Lee (2011) "Explaining the Female Black-White Obesity Gap: A Decomposition Analysis of Proximal Causes,” Demography, 48(4), $1429-1450$.

Johnston, Bradley C., Steve Kanters, Kristofer Bandayrel, Ping Wu, Faysal Naji, Reed A. Siemieniuk, Geoff D.C. Ball, Jason W. Busse, Kristian Thorlund, Gordon Guyatt, Jeroen P. Jansen, and Edward J. Mills (2014) “Comparison of Weight Loss Among Named Diet Programs in Overweight and Obese Adults. A Meta-Analysis," JAMA, 312(9), 923-933.

Kaczynski, Andrew T., Stephen R. Manske, Roger C. Mannell, and Keerat Grewal (2008) "Smoking and Physical Activity: A Systematic Review," American Journal of Health Behavior, 32(1), 93-110.

Kaneko, K., C. Ito, K. Koizumi, S. Watanabe, Y. Umeda, and K. Ishikawa-Takata (2013) "Resting Energy Expenditure (REE) in Six-to Seventeen-Year-Old Japanese Children and Adolescents," Journal of Nutritional Science and Vitaminology, 59(4), 299-309.

Katanoda, Kota, and Yasuhiro Matsumura (2002) "National Nutrition Survey in Japan - Its Methodological Transition and Current Findings," Journal of Nutritional Science and Vitaminology, 48(5), 423-432.

Katanoda, Kota, Hiroshi Nitta, Kunihiko Hayashi, and Yasuhiro Matsumura (2005) "Is the National Nutrition Survey in Japan Representative of the Entire Japanese Population?" Nutrition, 21(9), 964-966.

Livesey, Geoffrey, Richard Taylor, Toine Hulshof, and John Howlett (2008) “Glycemic Response and Health - A Systematic Review and Meta-Analysis: Relations between 
Dietary Glycemic Properties and Health Outcomes," American Journal of Clinical Nutrition, 87(1), 258S-268S.

Mesas, A.E., M. Muñoz-Pareja, E. López-García, and F. Rodríguez-Artalejo (2012) “Selected Eating Behaviours and Excess Body Weight: A Systematic Review,” Obesity Reviews, 13(2), 106-135.

Miles-Chan, J.L., D. Sarafian, J.P. Montani, Y. Schutz, and A.G. Dulloo (2014) "Sitting Comfortably versus Lying Down: Is There Really a Difference in Energy Expenditure?" Clinical Nutrition, 33(1), 175-178.

Ministry of Agriculture, Forestry and Fisheries (2015) Food Balance Sheet (in Japanese). http://www.maff.go.jp/j/tokei/kouhyou/zyukyu/index.html. Accessed Apr. 24, 2015. Ministry of Internal Affairs and Communications (2015) Survey on Time Use and Leisure Activities (in Japanese). http://www.stat.go.jp/data/shakai/2011/h23kekka.htm. Accessed April 12, 2015.

Ministry of Health, Labour and Welfare (2000) Healthy Japan 21 (in Japanese).

http://www1.mhlw.go.jp/topics/kenko21_11/pdf/all.pdf. Accessed December 26, 2016. Miyake, Rieko, Shigeho Tanaka, Kazunori Ohkawara, Kazuko Ishikawa-Takata, Yuki Hikihara, Emiko Taguri, Jun Kayashita, and Izumi Tabata (2011) "Validity of Predictive Equations for Basal Metabolic Rate in Japanese Adults,” Journal of Nutritional Science and Vitaminology, 57(3), 224-232.

Molnár, Dénes, Sára Jeges, Eva Erhardt, and Yves Schutz (1995) “Measured and Predicted Resting Metabolic Rate in Obese and Nonobese Adolescents," Journal of Pediatrics, 127(4), 571-577.

Okubo, H., S. Sasaki, H.H. Rafamantanantsoa, K. Ishikawa-Takata, H. Okazaki, and I. Tabata (2008) "Validation of Self-Reported Energy Intake by a Self-Administered Diet 
History Questionnaire Using the Doubly Labeled Water Method in 140 Japanese Adults," European Journal of Clinical Nutrition, 62(11), 1343-1350.

Patel, Sanjay R., and Frank B. Hu (2008) “Short Sleep Duration and Weight Gain: A Systematic Review,” Obesity, 16(3), 643-653.

Pieroni, Luca, and Luca Salmasi (2015) "Does Cigarette Smoking Affect Body Weight? Causal Estimates from the Clean Indoor Air Law Discontinuity," Economica, 82(328), 595-993.

Pieroni, Luca, and Luca Salmasi (2016) "The Effect of Smoking Habit Changes on Body Weight: Evidence from the UK," Economics and Human Biology, 20, 1-13. Rashad, Inas (2006) "Structural Estimation of Caloric Intake, Exercise, Smoking, and Obesity," Quarterly Review of Economics and Finance, 46(2), 268-283.

Riera-Crichton, Daniel, and Nathan Tefft (2014) "Macronutrients and Obesity: Revisiting the Calories In, Calories Out Framework," Economics and Human Biology, 14, 33-49. Robertson, Lindsay, Rob McGee, and Robert J. Hancox (2014) “Smoking Cessation and Subsequent Weight Change," Nicotine \& Tobacco Research, 16(6), 867-871. Schwingshack1, L., and G. Hoffmann (2013) "Long-Term Effects of Low Glycemic Index/Load vs. High Glycemic Index/Load Diets on Parameters of Obesity and Obesity-Associated Risks: A Systematic Review and Meta-Analysis," Nutrition, Metabolism \& Cardiovascular Diseases, 23(8), 699-706.

Statistics Bureau (2015) Historical statistics of Japan.

http://www.stat.go.jp/english/data/chouki/index.htm. Accessed Apr. 24, 2015.

Swinburn, Boyd A., Gary Sacks, Sing Kai Lo, Klaas R.Westerterp, Elaine C.Rush, Michael Rosenbaum, Amy Luke, Dale A. Schoeller, James P. DeLany, Nancy F. Butte, and Eric Ravussin (2009) "Estimating the Changes in Energy Flux that Characterize the 
Rise in Obesity Prevalence," American Journal of Clinical Nutrition, 89(6), 17231728.

Swinburn, Boyd A., Gary Sacks, Kevin D.Hall, Klim McPherson, Diane T. Finegood, Marjory L. Moodie, and Steven L. Gortmaker (2011) “The Global Obesity Pandemic: Shaped by Global Drivers and Local Environments," Lancet, 378(9793), 804-814.

Wehby, George L., Jeffrey C. Murray, Allen Wilcox, and Rolv T. Lie (2012) "Smoking and Body Weight: Evidence Using Genetic Instruments," Economics and Human Biology, 10(2), 113-126.

Wycherley, Thomas P., Lisa J.Moran, Peter M. Clifton, Manny Noakes, and Grant D. Brinkworth (2012) "Effects of Energy-Restricted High-Protein, Low-Fat Compared with Standard-Protein, Low-Fat Diets: A Meta-Analysis of Randomized Controlled Trials," American Journal of Clinical Nutrition, 96(6), 1281-98. 
Figure A1: Trends in BMI, $E$, and $K$ - Single-Person Households
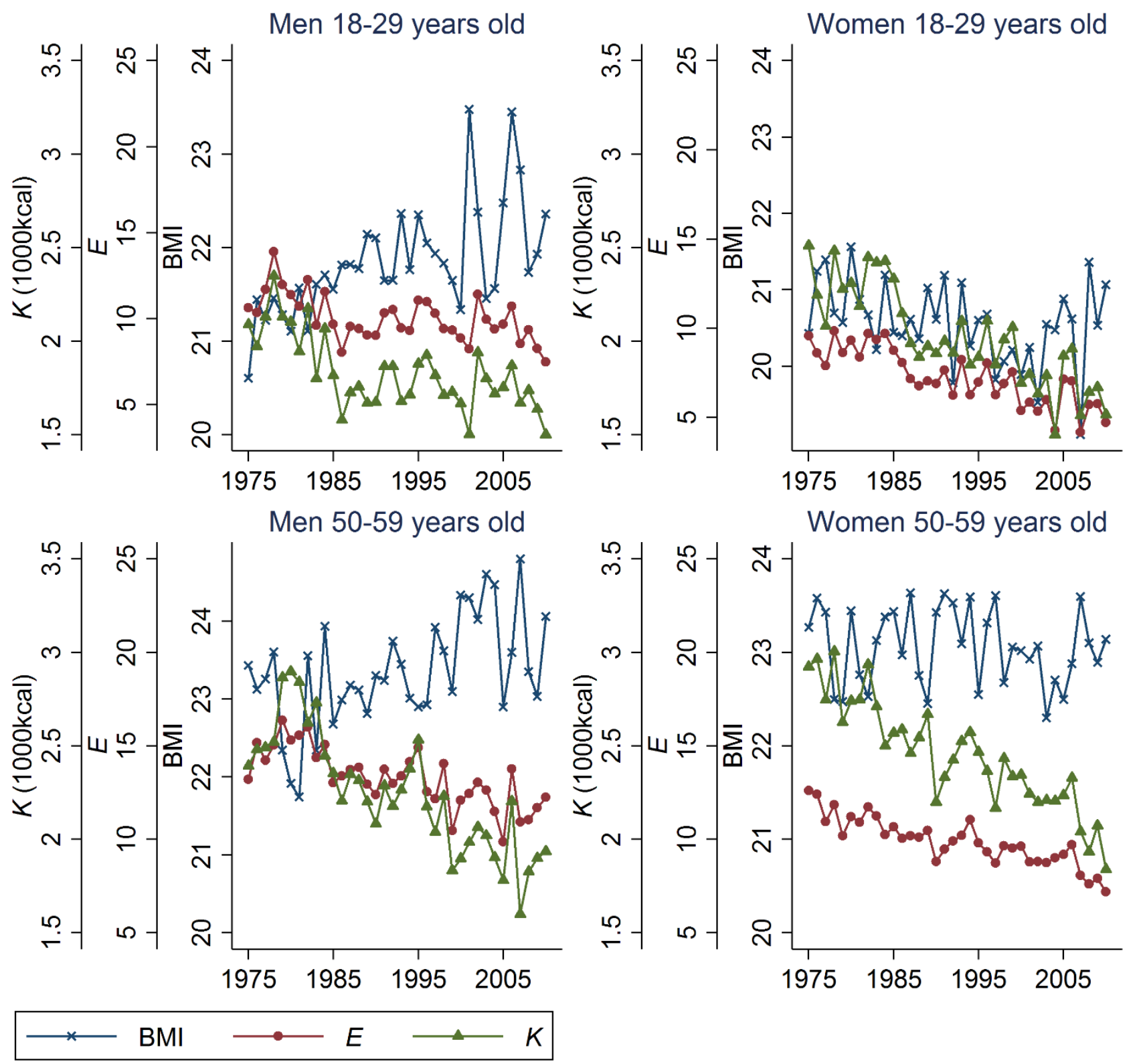

Notes: The horizontal axis indicates the survey year. $E$ is an index of the physical activity level calculated by the steady-state model, and $K$ is the daily energy intake (in 1,000 kcal). 
Figure A2: Decomposition by Occupation
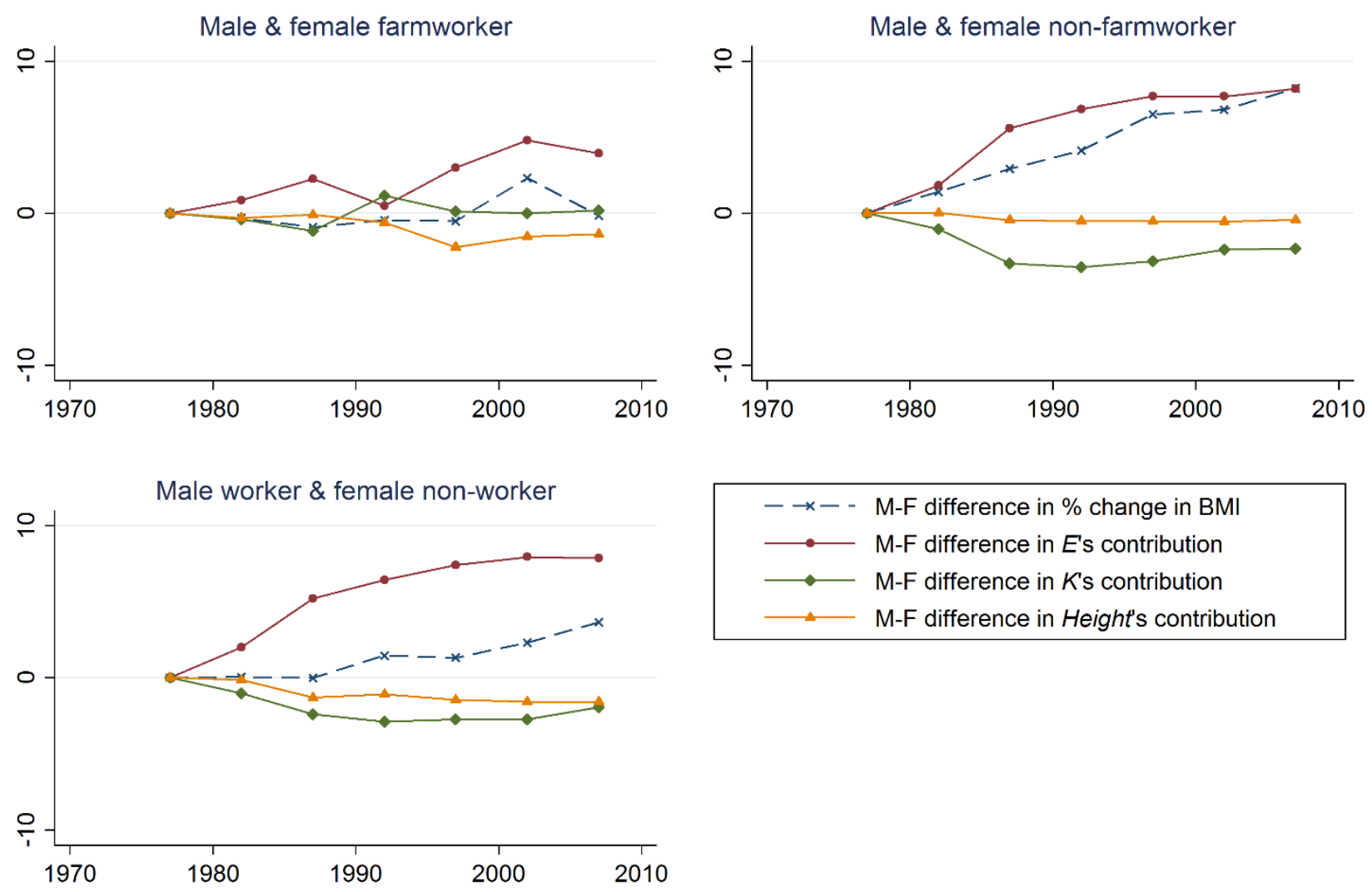

Notes: Based on individuals aged 22-59. $E$ is an index of the physical activity level calculated by the steady-state model, and $K$ is the daily energy intake. The male-female difference in percentage change in BMI was adjusted for the change in mean age in each year, i.e., ([\% change in the male BMI]-[\% change in the female BMI] $)-([\%$ change in age's contribution to the male $B M I]-[\%$ change in age's contribution to the female BMI])). The male-female difference in contributions refers to the male-female difference in cumulative percentage change in the contributions of $E, K$, and height relative to the base period, 1975-1979 (e.g., [\% change in E's contribution to the male BMI]-[\% change in E's contribution to the female $B M I)$. 
Figure A3: Trends in Per Capita Energy Supply, Energy Intake, and Food Price

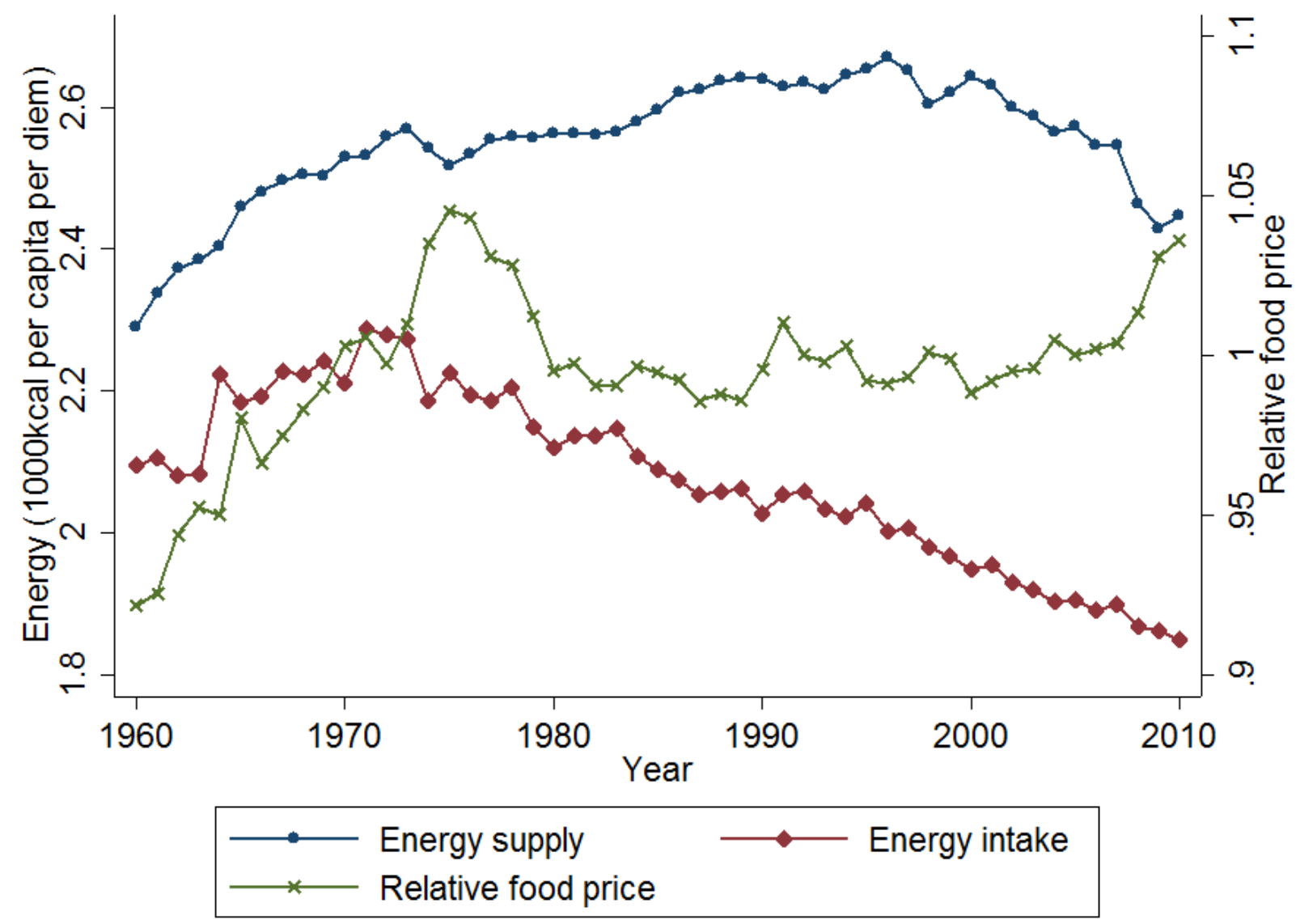

Notes: The relative food price is defined as the 2005 food price index divided by the 2005 consumer price index.

Sources: Statistics Bureau (2015) and Ministry of Agriculture, Forestry and Fisheries (2015). 
Figure A4: Trends in the Proportion of Energy Intake from Fat

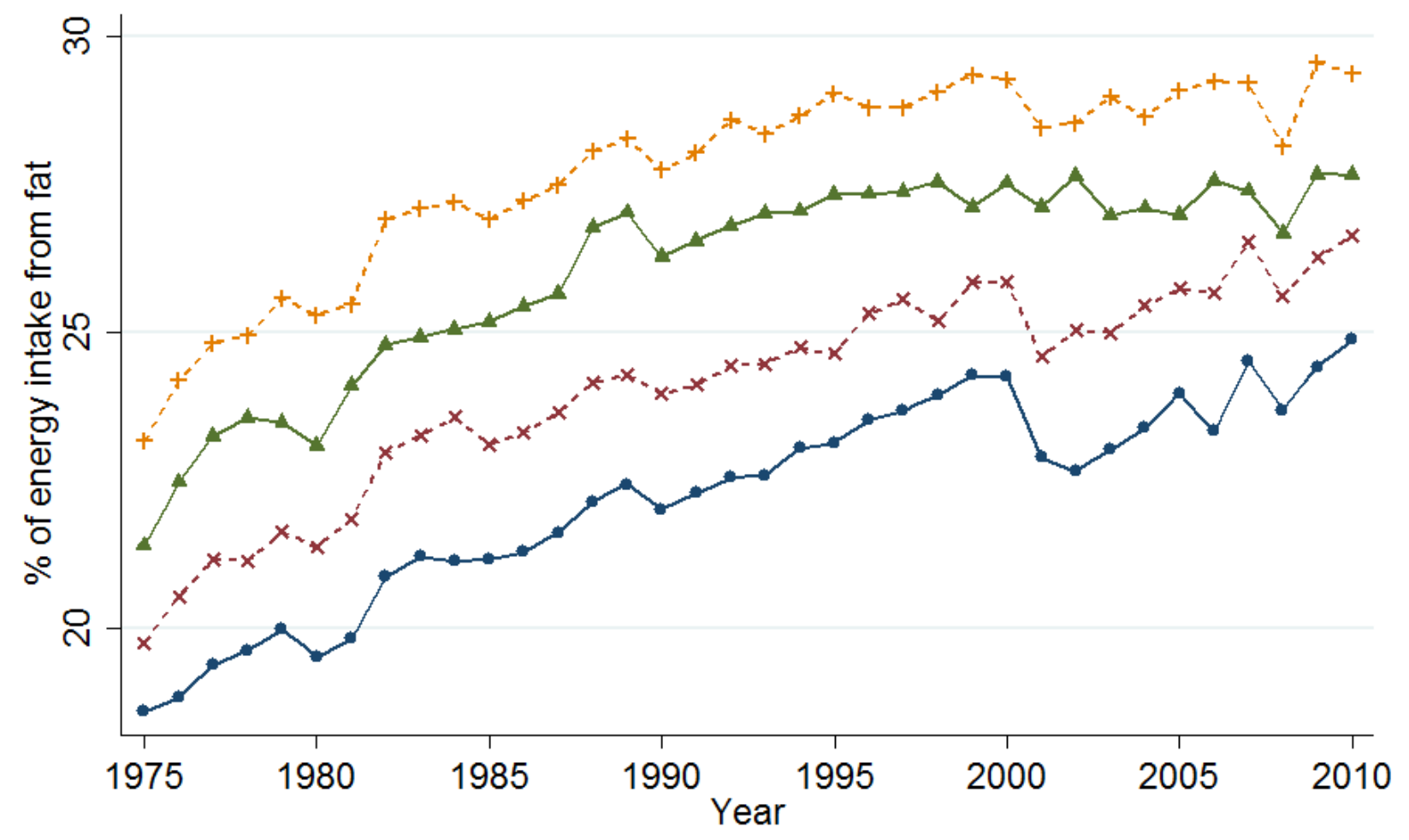

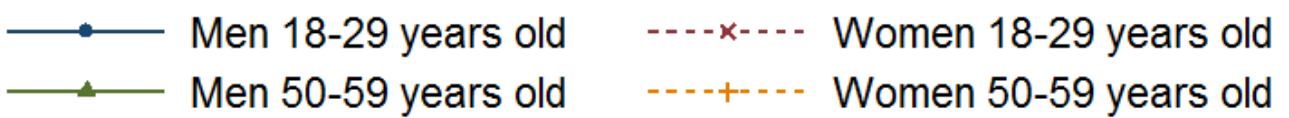

Notes: The percentage indicates the proportion of energy intake from fat during the survey period among the NNS respondents. 
Figure A5: Trends in the Percentage of Individuals who Eat between Meals Every Day

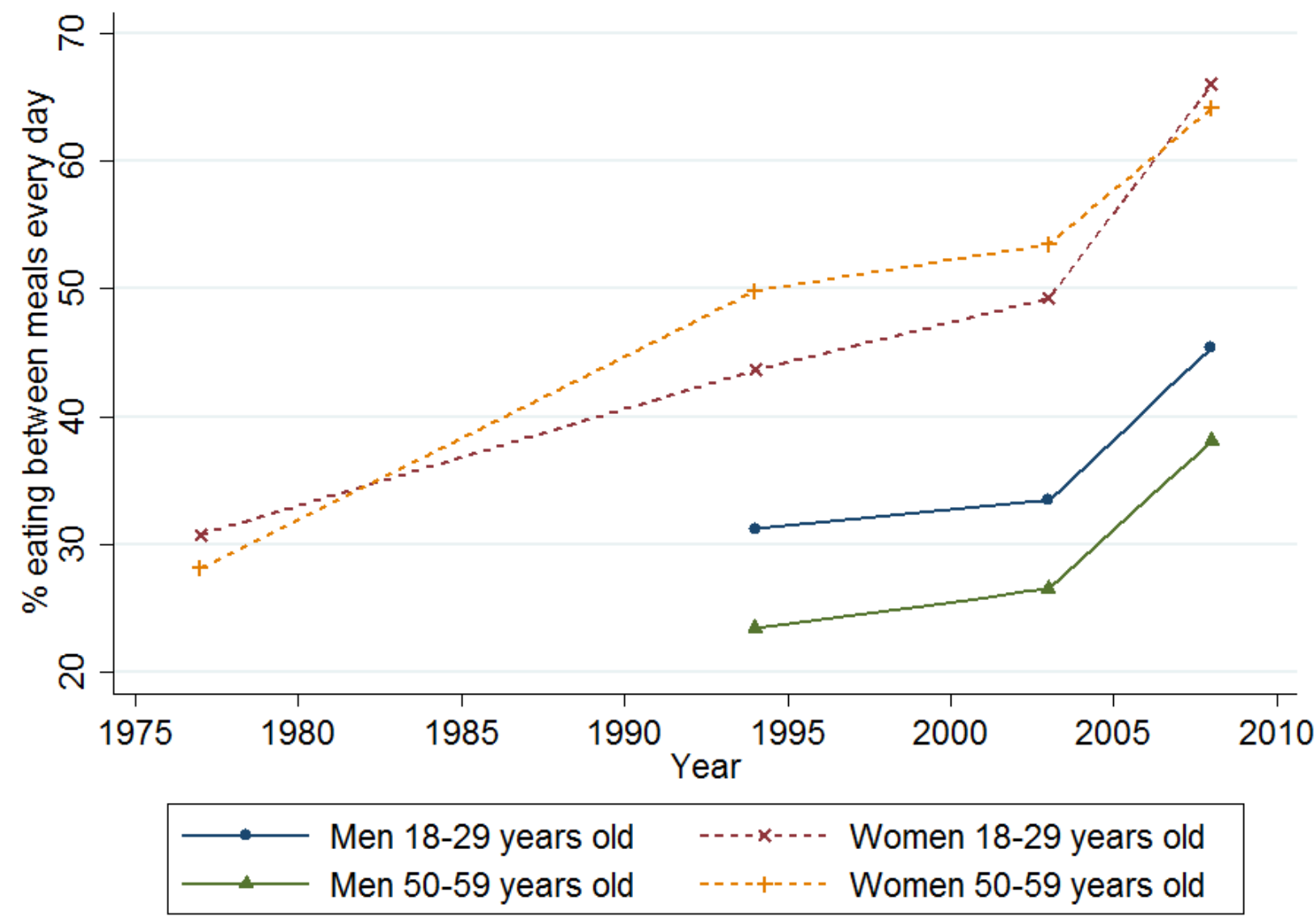

Notes: The percentage indicates the ratio of NNS respondents who ate between meals every day in 1977, mostly once or more per day in 1994, and seven times or more per week in 2004 and 2008. Information on men's eating habits is not available for 1977. 
Figure A6: Trends in the Percentage of Breakfasts Skipped

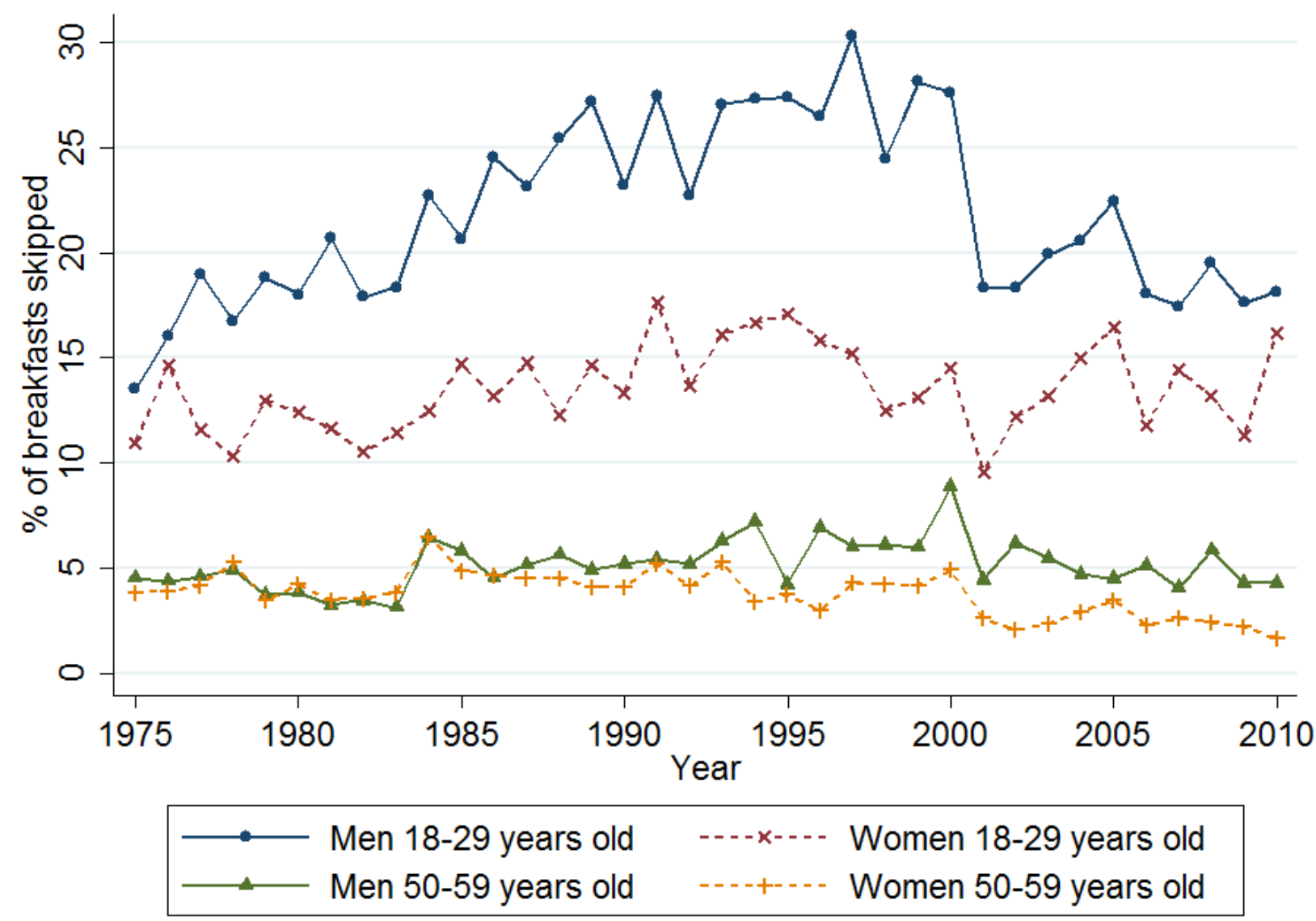

Notes: The percentage indicates the ratio of breakfasts skipped by NNS respondents during the survey period. The survey period was reduced from three consecutive days to one day in 1995. 
Figure A7: Trends in the Smoking Rate

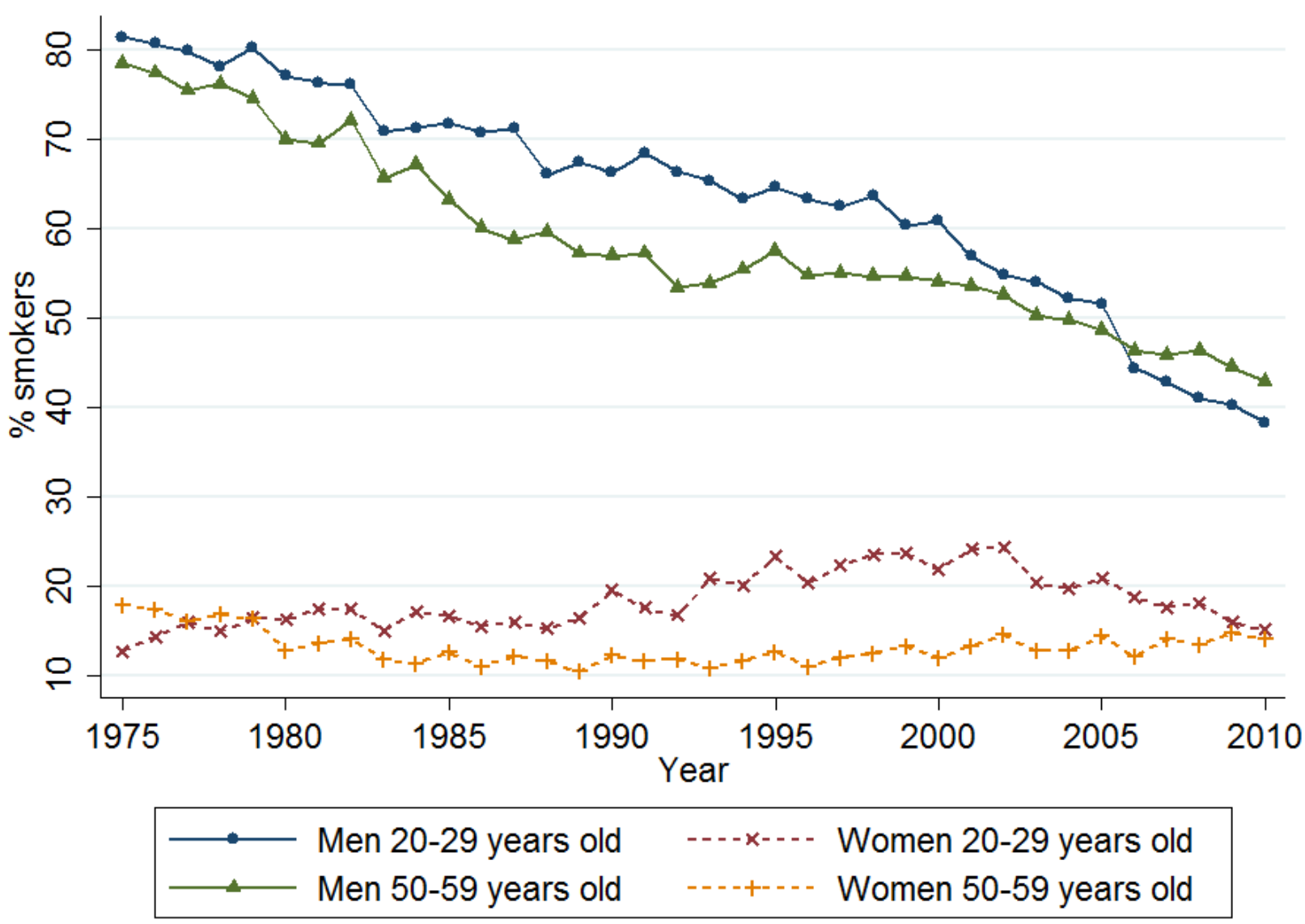

Source: Japan Tobacco Inc. (2015). 
Figure A8: Trends in Sleeping Hours

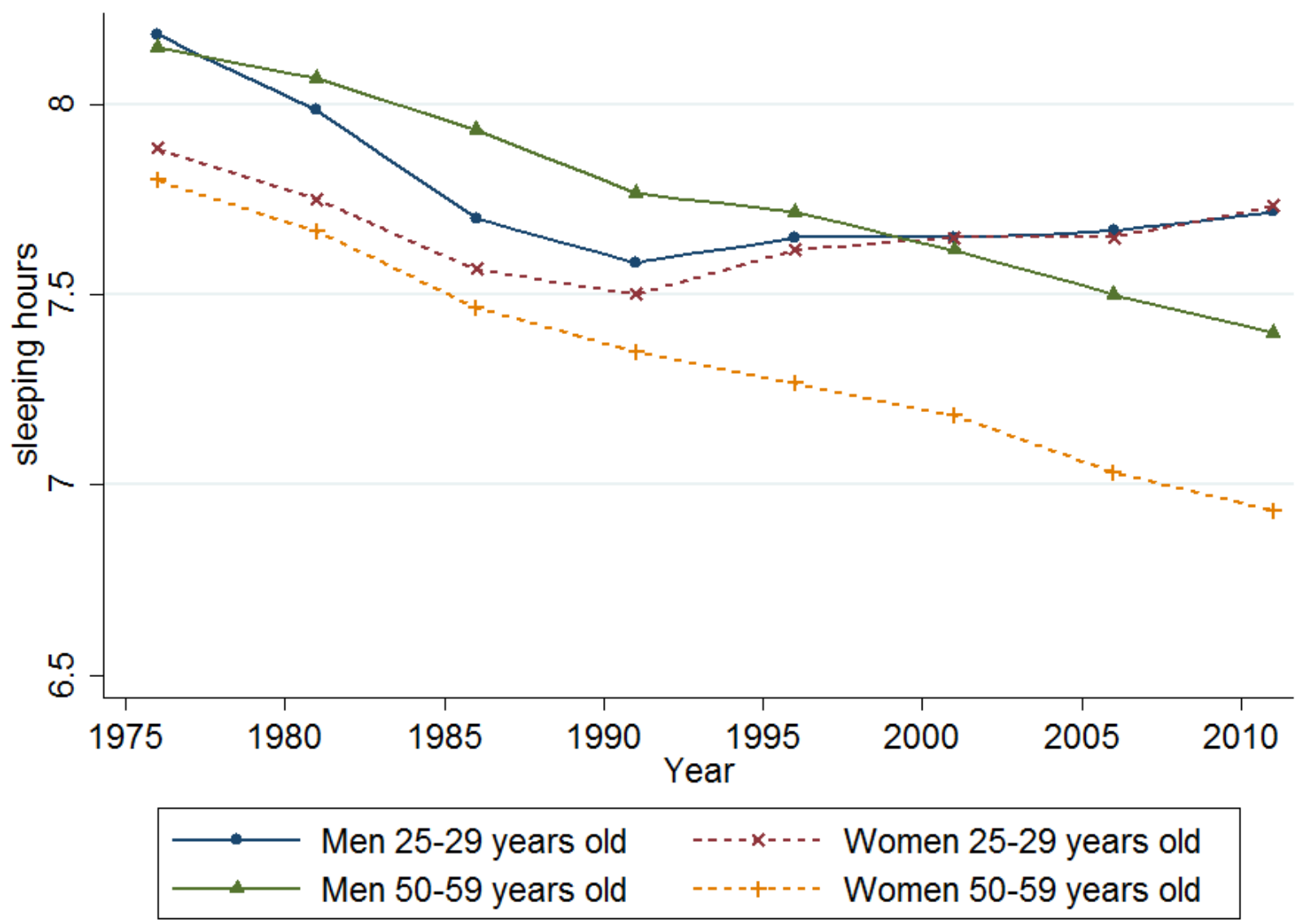

Source: Ministry of Internal Affairs and Communications (2015). 
Table A1: Decomposition of BMI Changes between 1975-1979 and 2001-2010

\begin{tabular}{|c|c|c|c|c|c|c|c|c|c|c|}
\hline \multirow[t]{2}{*}{ Gender } & \multirow[t]{2}{*}{ Age } & \multicolumn{2}{|c|}{$\begin{array}{l}\text { Number of } \\
\text { observations }\end{array}$} & \multicolumn{4}{|c|}{$\%$ change between the two periods } & \multicolumn{3}{|c|}{$\begin{array}{l}\text { Contribution to } \% \text { change } \\
\text { in BMI (in } \% \text { points) }\end{array}$} \\
\hline & & $\begin{array}{l}1975 \\
-79\end{array}$ & $\begin{array}{l}2001 \\
-10\end{array}$ & BMI & $E$ & $K$ & Height & $E$ & $K$ & Height \\
\hline \multirow[t]{4}{*}{ Male } & $18-29$ & 4,902 & 3,449 & $3.6 \%$ & $-50.6 \%$ & $-14.8 \%$ & $2.1 \%$ & $28.3 \%$ & $-21.6 \%$ & $-5.3 \%$ \\
\hline & $30-39$ & 5,295 & 4,264 & $5.3 \%$ & $-58.7 \%$ & $-16.7 \%$ & $3.7 \%$ & $33.8 \%$ & $-23.4 \%$ & $-9.4 \%$ \\
\hline & $40-49$ & 5,564 & 4,351 & $5.3 \%$ & $-57.3 \%$ & $-15.9 \%$ & $4.4 \%$ & $33.7 \%$ & $-21.7 \%$ & $-11.0 \%$ \\
\hline & $50-59$ & 3,955 & 5,519 & $5.9 \%$ & $-48.7 \%$ & $-13.6 \%$ & $3.7 \%$ & $29.5 \%$ & $-18.2 \%$ & $-9.3 \%$ \\
\hline \multirow[t]{4}{*}{ Female } & $18-29$ & 6,257 & 3,799 & $-2.0 \%$ & $-45.7 \%$ & $-15.1 \%$ & $2.1 \%$ & $24.5 \%$ & $-21.5 \%$ & $-5.5 \%$ \\
\hline & $30-39$ & 7,813 & 5,007 & $-2.9 \%$ & $-46.8 \%$ & $-15.7 \%$ & $3.2 \%$ & $25.6 \%$ & $-21.5 \%$ & $-8.4 \%$ \\
\hline & $40-49$ & 7,540 & 5,348 & $-3.5 \%$ & $-43.0 \%$ & $-14.8 \%$ & $3.8 \%$ & $24.2 \%$ & $-19.3 \%$ & $-9.6 \%$ \\
\hline & $50-59$ & 5,620 & 6,957 & $-1.6 \%$ & $-37.1 \%$ & $-12.5 \%$ & $3.3 \%$ & $21.5 \%$ & $-15.8 \%$ & $-8.2 \%$ \\
\hline
\end{tabular}

Notes: $E$ is an index of the physical activity level calculated by the steady-state model, and $K$ is the daily energy intake. Even within the same age group, the mean age differs slightly by survey year due to a small change in the age composition. Hence, we decomposed the changes in BMI to the changes in $E$, $K$, height, and age but omitted the results for age from the table because its contribution is negligible (within $\pm 0.1 \%$ ). The contributions of $E, K$, height, and age do not necessarily sum to $100 \%$ due to negligible residuals in the Taylor expansion. 